\begin{tabular}{|c|c|c|c|c|c|c|}
\hline \multicolumn{7}{|c|}{ DISTRIBUTION SHEET } \\
\hline To & \multirow{2}{*}{\multicolumn{4}{|c|}{$\begin{array}{l}\text { From } \\
\text { Packaging Programs \& Testing }\end{array}$}} & \multicolumn{2}{|c|}{ Page 1 of 1} \\
\hline Distribution & & & & & \multicolumn{2}{|c|}{ Date $01 / 23 / 95$} \\
\hline \multirow{2}{*}{\multicolumn{5}{|c|}{$\begin{array}{l}\text { Project Title/Work Order } \\
\text { DOT-7A Type A Packaging Design Guide }\end{array}$}} & \multicolumn{2}{|c|}{ EDT No. 608457} \\
\hline & & & & & \multicolumn{2}{|c|}{ ECN No. } \\
\hline Name & & MSIN & $\begin{array}{c}\text { Text } \\
\text { With All } \\
\text { Attach. }\end{array}$ & Text Only & $\begin{array}{l}\text { Attach.l } \\
\text { Appendix } \\
\text { Only }\end{array}$ & $\begin{array}{l}\text { EDT/ECN } \\
\text { Only }\end{array}$ \\
\hline \multicolumn{7}{|c|}{ Westinghouse Hanford Company } \\
\hline $\begin{array}{l}\text { J. G. Field } \\
\text { D. L. Kelly } \\
\text { D. L. McCall } \\
\text { J. H. O'Brien } \\
\text { DOT-7A File } \\
\text { Central Files (orig. +2) } \\
\text { OSTI (2) }\end{array}$ & & $\begin{array}{l}G 2-02 \\
G 2-02 \\
G 2-02 \\
G 2-02 \\
G 2-02 \\
\text { L8-04 } \\
\text { L8 }-07\end{array}$ & $\begin{array}{l}X \\
X \\
X \\
X \\
X \\
X \\
X\end{array}$ & & & \\
\hline
\end{tabular}

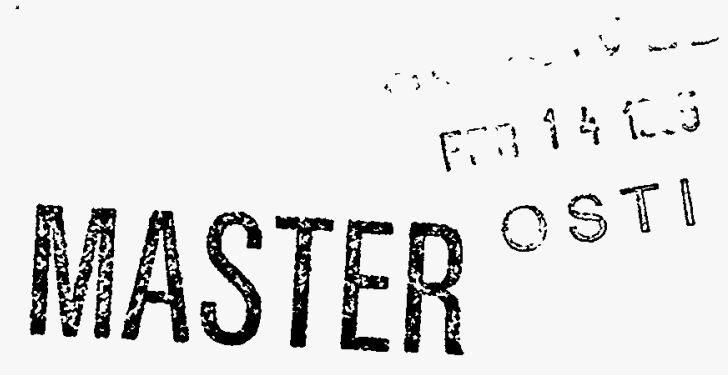




\section{DISCLAIMER}

Portions of this document may be illegible in electronic image products. Images are produced from the best available original document. 
4

अव.श

JAN $3019955^{\circ}$ OENGINEERING DATA TRANSMITTAL

Page 1 of 1

1. EDT 608457

2. To: (Receiving Organization)

Packaging Programs \& Testing

5. Proj./Prog./Dept./Div.:

84400/YHXAA

8. Originator Remarks:

11. Receiver Remarks:
3. From: (Originating Organization) Packaging Programs \& Testing

6. Cog. Engr.:

D. L. Kelly

4. Related EDT No.:

$N / A$

7. Purchase order No.: $N / A$

9. Equip./Component No.: $N / A$

10. System/Bldg./Facility: $N / A$

12. Major Assm. Dwg. No.: $N / A$

13. Permit/Permit Application No.: N/A

14. Required Response Date:

$01 / 30 / 95$

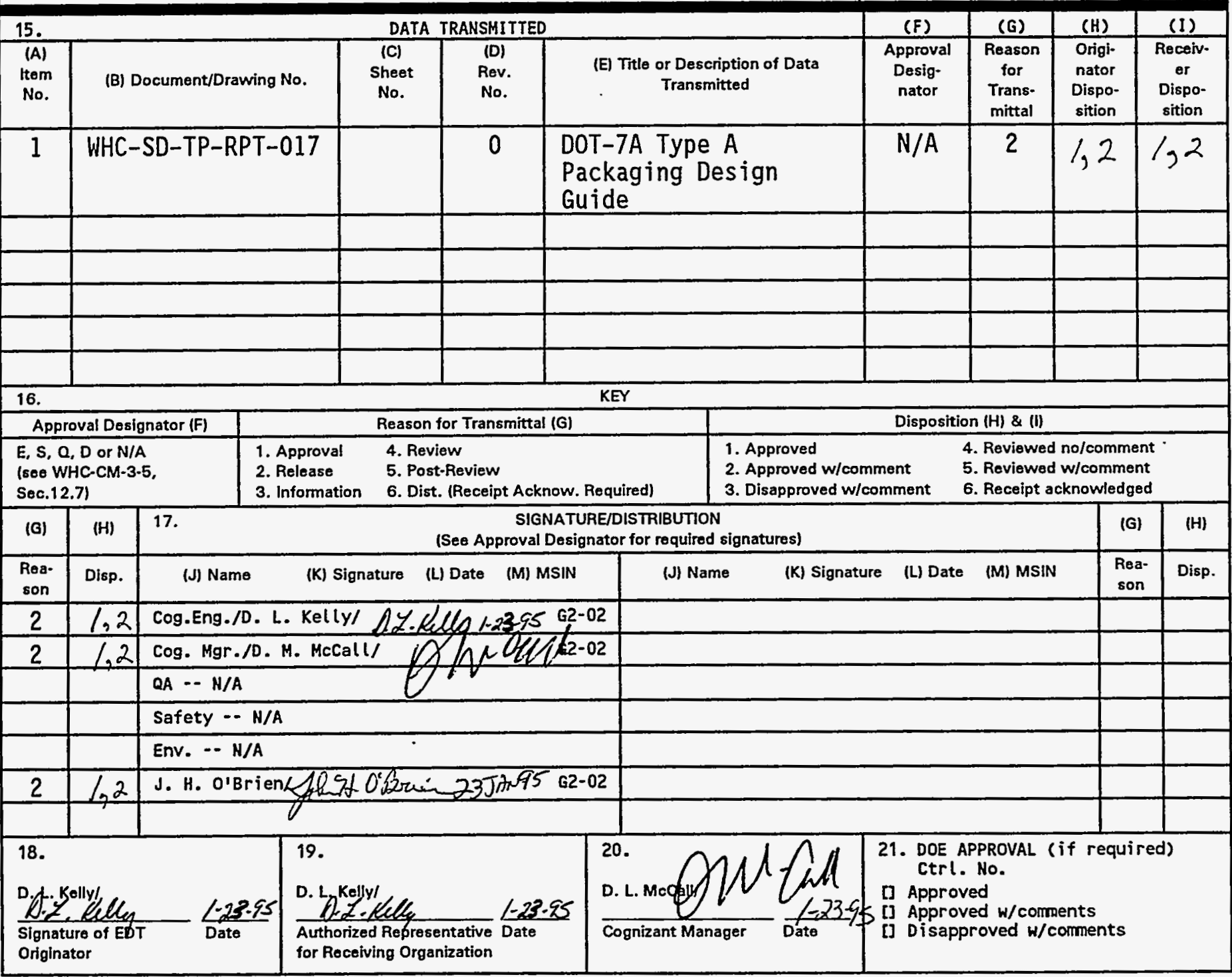




\section{RELEASE AUTHORIZATION}

Document Number: WHC-SD-TP-RPT-017, REV. 0

Document Title: DOT-7A TYPE A PACKAGING DESIGN GUIDE

Release Date: $\quad 1 / 24 / 95$

\section{This document was reviewed following the procedures described in WHC-CM-3-4 and is:}

APPROVED FOR PUBLIC RELEASE

WHC Information Release Administration Specialist:

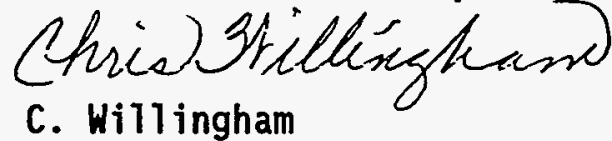

c. Willingham

TRADEMARK DISCLAIMER. Reference herein to any specific commercial product, process, or service by trade name, trademark, manufacturer, or otherwise, does not necessarily constitute or imply its endorsement, recommendation, or favoring by the United States Goverment or any agency thereof or its contractors or subcontractors.

This report has been reproduced from the best ovailable copy. Available in paper copy and microfiche. Printed in the United States of America. Available to the U.S. Department of Energy and its contractors from:

U.S. Department of Energy

office of Scientific and Technical Information (OSTI)

P.0. Box 62

Dak Ridge, TH 37831

Telephone: (615) 576-8401

Available to the public from: U.S. Department of Comerce

National Technical Information Service (NTIS)

5285 Port Royal Rood

Springfield, VA 22161

Telephone: (703) 487-4650

\section{DISCLAIMER}

This report was prepared as an account of work sponsored by an agency of the United States Government. Neither the United States Government nor any agency thereof, nor any of their employees, makes any warranty, express or implied, or assumes any legal liability or responsibility for the accuracy, completeness, or usefulness of any information, apparatus, product, or process disclosed, or represents that its use would not infringe privately owned rights. Reference herein to any specific commercial product, process, or service by trade name, trademark, manufacturer, or otherwise does not necessarily constitute or imply its endorsement, recommendation, or favoring by the United States Government or any agency thereof. The views and opinions of authors expressed herein do not necessarily state or reflect those of the United States Government or any agency thereof. 


\begin{tabular}{|l|l|l|}
\hline $\begin{array}{l}\text { 2. Title } \\
\text { DOT-7A TYPE A PACKAGING DESIGN GUIDE }\end{array}$ & $\begin{array}{l}\text { 3. Number } \\
\text { WHC-SD-TP-RPT-017 }\end{array}$ & 4. Rev No. \\
\hline $\begin{array}{l}\text { 5. Key Words } \\
\text { Design Guide, DOT-7A, Type A, Package, Packaging, } \\
\text { Radioactive Materia1 }\end{array}$ & $\begin{array}{l}\text { 6. Author } \\
\text { Name: D. L. Kel1y }\end{array}$ \\
\hline
\end{tabular}

\section{Abstract}

This report outlines the DOT-7A Type A Packaging Design Guide that was drafted by D. L. Kelly in 1994. Please note that this report is not in WHC format. This report is being submitted through the Engineering Documentation System so that it may be used for reference and information purposes.

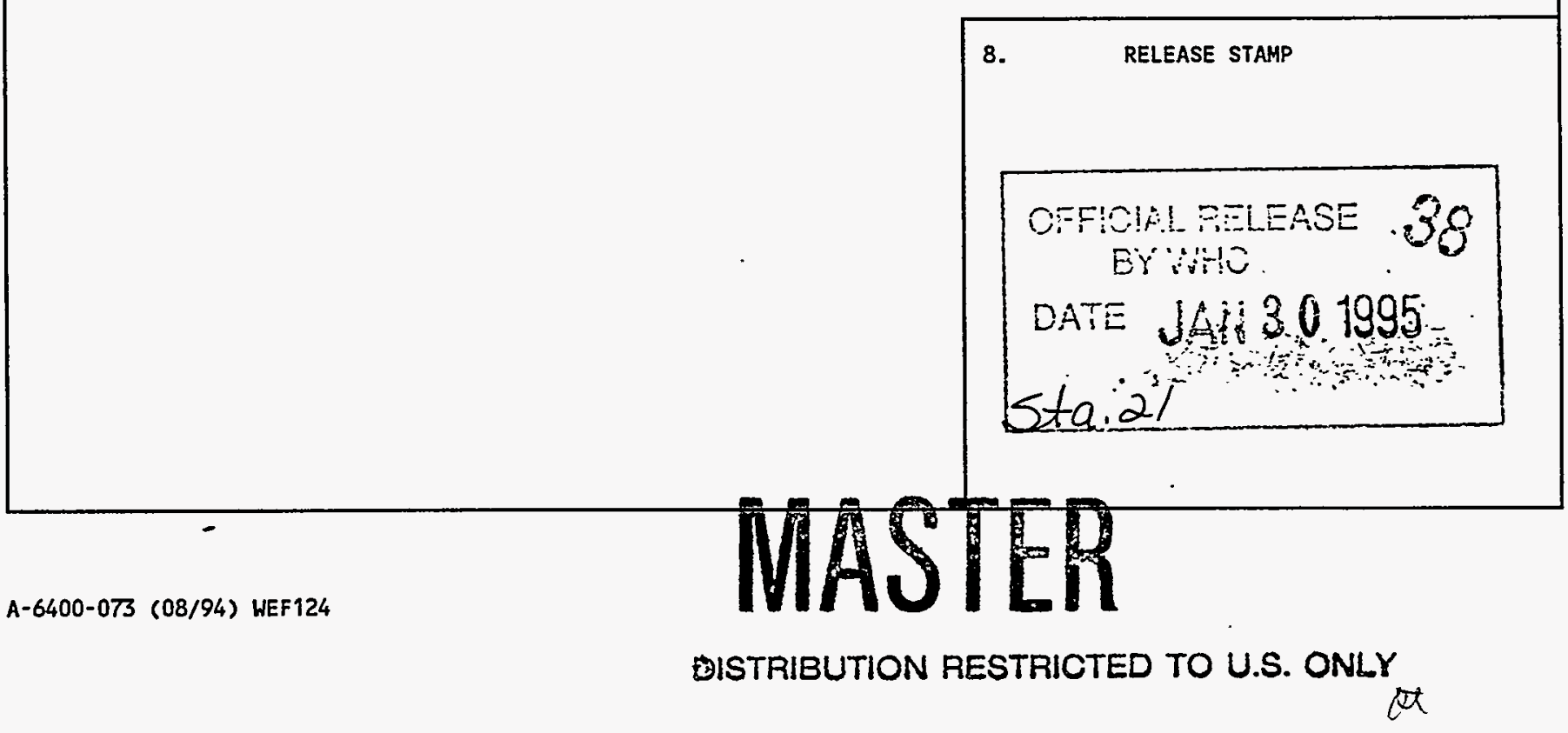


WHC-SD-TP-RPT-017

Revision 0

\section{CONTENTS}

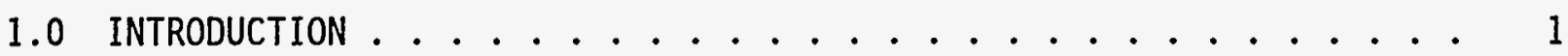

2.0 CHARACTERIZATION OF CONTENTS . . ............ 2

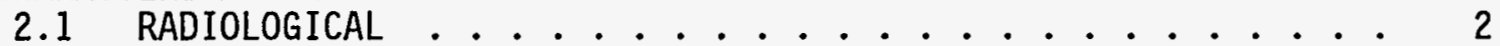

2.2 PHYSICAL FORM ...................... 3

2.3 THERMAL ....................... 4

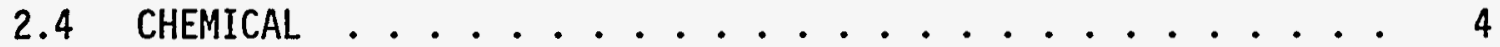

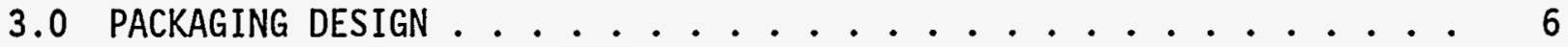

3.1 GENERAL ARRANGEMENT . ................ 6

3.2 CONTAINMENT . . . . . . . . . . . . . . . 6

3.3 SHIELDING ........................... 7

3.4 LIFTING AND HANDLING ................ 8

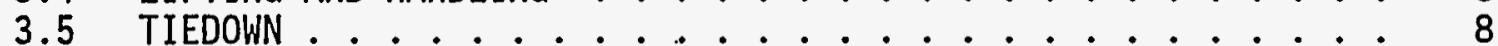

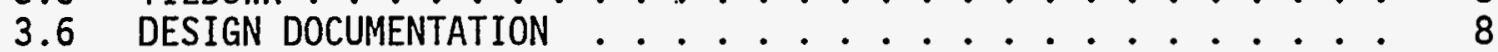

3.6 .1 Drawing ................ 8

3.6.2 Specification ............... . . . 9

3.6.3 Analysis Report ............... 10

4.0 PACKAGING OPERATIONS ........................ 10

4.1 GENERAL ....................... 10

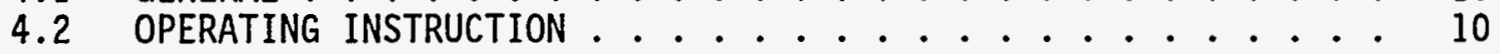

5.0 PACKAGING QUALIFICATION CHECKLIST . . . . . . . . . 12

6.0 PREPARATIONS FOR TESTING . . . . . . . . . . . . 12

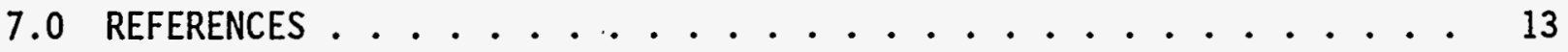

8.0 GLOSSARY . . . . . . . . . . . . . . . 13

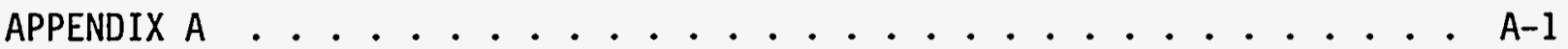

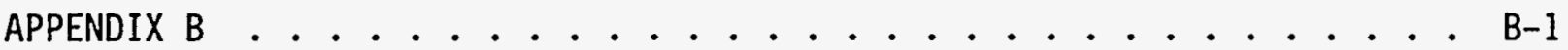


WHC-SD-TP-RPT-017

Revision 0

\subsection{INTRODUCTION}

The purpose of this Design Guide is to provide instruction for designing a U.S. Department of Transportation Specification 7A (D0T-7A) Type A packaging. Another purpose for this Design Guide is to support the evaluation and testing activities that are performed on new designs by a U.S. Department of Energy (DOE) test facility. The test facilities are located at various DOE facilities and are operated under the direction of DOE-Headquarters (HQ), Transportation and Packaging Safety Division (EH-332). This evaluation and testing program is called the DOT-7A Program.

The use of this Design Guide is invoked when a need for a Type A packaging has been identified, and no currently qualified design or any design available from commercial suppliers will suffice. In this case, the organization responsible for the shipments (the shipper) must develop a packaging and qualify the packaging through the DOEDDOT-7A Program. The person or organization sponsoring the development activity is referred to herein as the applicant.

The development process is initiated when the applicant has determined that a DOT-7A, Type A packaging is needed and that no currently qualified designs or commercially available designs will suffice. Characterization of the material to be shipped should have already been performed to the extent needed to conclude that no available packagings will be adequate. Design of a packaging will require the material to be characterized to some minimal level to ensure that the new design will be adequate. Accordingly, the first step in this Design Guide is focused on content characterization, which will generate some important parameters to be considered in the design process.

The design of a DOT-7A, Type A packaging, in accordance with this document, will generate the following items. These items are to be forwarded to a DOE/HQ-approved test facility for review before the evaluation and testing activities.

- $\quad$ Packaging drawing

- Packaging specification

(Optional, if needed to supplement drawing)

- Analysis report

- Operating instruction

- Packaging Qualification Checklist (PQCL).

The design process will result in completion of a PQCL (see Appendix B). The DOE/HQ-approved test facility DOT-7A Program team will review these 
WHC-SD-TP-RPT-017

Revision 0

documents and resolve any comments with the applicant. The applicant will then prepare a sufficient number of prototype test units to satisfy the test requirements. The test units are then sent to the DOE/HQ-approved test facility where the final evaluations and performance testing are completed.

Packagings must be designed such that when subjected to the tests specified in 49 CFR 173.465 or evaluated against these tests by any of the methods authorized by 49 CFR 173.461(a), the packaging will prevent loss or dispersal of the radioactive contents, and any significant increase in the radiation levels recorded or calculated at the external surfaces for the condition before the test [49 CFR $173.412(\mathrm{~m})$ ].

The following sections detail the design process and the steps necessary to prepare for testing. Suggestions based on experience to date for materials and configurations are also included in the following sections.

\subsection{CHARACTERIZZATION OF CONTENTS}

This section of the Design Guide establishes what is considered the minimum level of characterization of the material to be shipped to support the design of a suitable packaging. It is not intended to define all aspects of content characterization that may be needed to fully document a shipment. The shipper is responsible for adequate content characterization to a level of detail to ensure compliance with the regulations.

\subsection{RADIOLOGICAL}

The following sections of Title 49 Code of Federal Regulations (49 CFR) that pertain to the radiological characteristics of the material to be shipped:

173.417 Authorized packaging--fissile materials

173.431 Activity limits for Type $A$ and Type $B$ packages

173.433 Requirements for determination of $A_{1}$ and $A_{2}$ values for radionuclides

173.441 Radiation level Timitations

173.451 Fissile materials--general requirements

173.453 Fissile materials--exceptions

173.455 Classification of fissile materials packages

173.459 Mixing of fissile material packages.

Addressing these requirements for the purpose of packaging design will require the development of a design basis 7 ist of the isotopes to be present in the contents and their expected quantity on a per-loaded-package basis 
WHC-SD-TP-RPT-017

Revision 0

(isotopic inventory). This 1 ist will be used for design purposes and will not reflect the actual contents shipped; but should establish bounding values on actual contents for design purposes. The applicant is requested to provide this list in the appropriate area in the checklist of Appendix B. Further, if fissile radionuclides are present, the fissile classification shall be indicated.

The important parameters are (1) total activity allowed in the packaging, and (2) radiation level limits. Decay heat is covered in Section 2.3, Therma?.

\subsection{PHYSICAL FORM}

The physical form of the material has a direct and an indirect effect on the applicability of a number of requirements; for example, the form affects the density of the material, which will affect the gross weight, which affects the requirements invoked for package handling features. The Contents Characterization section of Appendix B contains check off blocks for the basic physical form of the material to be shipped with blanks for additional data, based on the form.

Solid materials are defined in WHC-EP-0558, "Test and Evaluation Document for DOT Specification 7A Type A Packaging," (Cruse, 1992), as follows:

Form Number 1: Solids - any particle size

- A packaging qualified for these contents is expected to contain radioactive contents of any representative particulate size.

Form Number 2: Solids - large particle size only (i.e., sand, concrete, debris, soil)

- Contents of a corresponding particulate size such as soil or construction debris. (Glass or plastic labware having fine particulate available for dispersion would not fit this category and would require a packaging qualified for fine particulate, Form Number 1.)

Form Number 3: Solids - objects with no significant dispersible or removable contamination (for definition, see 49 CFR 173.443, Contamination Control).

- Metals with activation products

- Forms of metals/alloys/compounds of uranium, thorium 
WHC-ȘD-TP-RPT-017

Revision 0

- Solid materials with the radioactive material firmly fixed in place, possibly by the application of a fixing media (i.e., paint)

- Solidified material.

NOTE: These are examples only and each form must be analyzed for compliance with the "no removable or dispersible contamination"

criterion found in 49 CFR 173.443.

For heavy, bulky, materials (e.g., concrete chunks, motors, and pumps), equipment/materials with sharp corners or protrusions, or material/equipment geometries that could result in highly localized forces, the shipper must ensure that the contents are securely fastened/positioned within the package to prevent damage to the packaging.

Packaging intended to transport 7 iquids and gases must be designed to withstand more severe test conditions than those designed for solids.

\subsection{THERMAL} packagings:

The following sections of 49 CFR pertain to the thermal limitations of

173.412(d) Containment and shielding - temperature range

173.442 Thermal Timitations

173.448 (b) Heat output.

For whatever reason the thermal heat generation of the contents must not degrade the packaging. Normally Type A quantities of radionuclides do not generate enough decay heat to be of concern. For any heat-generating contents, the decay heat should be calculated and documented in the package design analyzed to ensure no problems. The applicant shall indicate a maximum design wattage value for the contents in the appropriate block of Appendix $B$.

\subsection{CHEMICAL}

The following sections of 49 CFR pertain to the chemical characteristics of the contents:
173.21
173.24 (b) (3)
$173.24(\mathrm{e})(2)$
$173.24(\mathrm{e})(3)$
$173.24(\mathrm{f})$
$173.412(\mathrm{~g})$
$173.412(h)$

Forbidden materials and packages

Mixture, reaction

Reaction

Plastic compatibility/permeability

Closures, gaskets

Compatibility, behavior under irradiation

Gas generation, radiolysis. 
WHC-SD-TP-RPT-017

Revision 0

The contents must not react with the packaging so as to degrade it. The contents must not possess or develop chemical conditions that could lead to pressurization beyond design specification or an explosion.

The basic chemical makeup of the nonradioactive constituents of the contents to be shipped must be understood to adequately design a packaging. The applicant shall identify any nonradioactive materials in the contents that meet the definition of hazardous materials in accordance with 49 CFR 172 . The applicant shall also identify all organic substances and the quantity expected to be present in a single package. The hazardous materials shall be 1 isted by their proper shipping name and identification number in accordance with the Hazardous Materials Table. This information may be Tisted in the space provided in Appendix B.

Hydrogen gas generation has been a controlling parameter for a number of radioactive shipments. The U.S. Nuclear Regulatory Commission (NRC) has been including the following generic requirements in certain Certificates of Compliance (NRC, 1984):

(1) For any package containing water and/or organic substances that could radiolytically generate combustible gases, it must be determined by tests and measurements of a representative package whether or not the following criteria are met of a period of time that is twice the expected shipment time:

(a) The hydrogen generated must be limited to a molar quantity that would be no more than $5 \%$ by volume (or equivalent limits for other inflammable gases) of the secondary container gas void, if present, at STP (i.e., no more than $0.063 \mathrm{~g}$-moles/ft- $14.7 \mathrm{psia}$ and $70^{\circ} \mathrm{F}$ ), or

(b) The secondary container and cask cavity must be inerted with a diluent to ensure that oxygen must be limited to $5 \%$ by volume in those portions of the package that could have hydrogen greater than $5 \%$.

For any package delivered to a carrier for transport, the secondary container must be prepared for shipment in the same manner in which determination for gas generation is made. The shipment period begins when the package is prepared (sealed) and must be completed within twice the expected shipment time.

(2) For any package containing materials with radioactivity concentration not exceeding that for low specific activity (LSA) materia7, and shipped within 10 days of preparation, or within 10 days after venting of drums or other secondary containers, the 
WHC-SD-TP-RPT-017

Revision 0

determination in (1) above need not be made, and the time. restriction in (1) above does not apply.

\subsection{PACKAGING DESIGN}

The following sections of 49 CFR pertain to the design of a Type A packaging:

$$
\begin{aligned}
& 173.24(\mathrm{~b}) \\
& 173.24(\mathrm{e})(3) \\
& 173.411(\mathrm{a})-(\mathrm{f}) \\
& 173.412 \\
& 173.462(\mathrm{c}) \\
& 173.462(\mathrm{~d}) \\
& 178.3
\end{aligned}
$$

\author{
Design and construction \\ Plastic packagings and receptacles \\ General design requirements \\ Additional design requirements for Type A packages \\ Containment system ... specified \\ External features... clearly identified. \\ Marking of Packagings
}

The designer should scan the data in WHC-EP-0558, "Test and Evaluation Document for DOT Specification 7A Type A Packagings," (Cruse, 1992) and review designs that have been qualified for similar contents for examples from which to work. Before beginning the design process, all regulatory requirements should be thoroughly reviewed and understood. For convenience, the applicable design- related Type A packaging requirements have been excerpted and included as Appendix $A$ to this document. This material is for information onty and cannot guarantee reflection of the latest revisions of the applicable regulations.

\subsection{GENERAL ARRANGEMENT}

The packaging design will generally fall into one of three basic configurations: (1) single packaging, (2) composite packaging, or (3) combination packaging (see definitions 49 CFR 171.8). Single packagings are generally recommended for solids meeting the definition of Form Number 2 or Form Number 3, or gases. For packaging of solids classed as Form Number 1 and 7 iquids, composite or combination packagings are recommended.

\subsection{CONTAINMENT}

The following sections of 49 CFR pertain to containment of contents:
$173.24(b)$
$173.24(\mathrm{e})(2)$
$173.24(\mathrm{e})(3)$
$173.24(f)$
Design and construction
Reaction
Plastic packagings and receptacles
Closures and gaskets 
WHC-SD-TP-RPT-017

Revision 0

$173.462(c)$

$173.469(a)(4)$

Containment system . . specified

Leaktightness.

Basically, there can be "no significant release of the hazardous materials to the environment," and the packaging must remain effective when subjected to normal conditions of transport, with account being taken for any reactions between the contents and the packaging materials. In practice, "no significant release" implies no measurable leakage based on visual evaluation.

In certain tests, the leakage rate may be measured to a leak detection sensitivity of $1 \times 10^{-4} \mathrm{std}-\mathrm{cm}^{3} / \mathrm{s}$. In special form tests, the leakage rate shall be measured to a leak detection sensitivity of $1 \times 10^{-4}$ torr-1/s $\left(1.3 \times 10^{-4} \mathrm{~atm}-\mathrm{cm}^{3} / \mathrm{s}\right)$, based on air at $25^{\circ} \mathrm{C}\left(77^{\circ} \mathrm{F}\right)$ and one atmosphere differential pressure for solid radioactive content, or $1 \times 10^{-6}$ torr-1/s $\left(1.3 \times 10^{-6} \mathrm{~atm}-\mathrm{cm}^{3} / \mathrm{s}\right)$ for liquid or gaseous radioactive content.

Containment is formed by those materials or components that are or may be in direct contact with the contents during shipment. The design process will involve choices of basic material, use of filters or other pressure relief devices, gaskets or other seal materials, closure mechanisms, and other features. Typical containment materials are high-density polyethylene (HDPE), polypropylene, glass, and steel. The designer should review all of the design-related regulatory requirements and address them in the design process.

\title{
3.3 SHIELDING
}

The following sections of 49 CFR pertain to the design of shielding for Type A packagings:

\author{
173.412 (d) Temperature $\left(-40\right.$ to $70^{\circ} \mathrm{C}\left[-40\right.$ to $\left.\left.158{ }^{\circ} \mathrm{F}\right]\right)$, \\ brittle fracture \\ $173.412(k)$ Shieiding/containment interface \\ 173.441 Radiation level Timitations.
}

Shielding may be required for Type A quantities of radionuclides. Lead or steel are commonly used materials for shielding. The regulations require the shielding (if used), and containment systems of the packaging remain effective when subjected to normal conditions of transport. 
WHC-SD-TP-RPT-017

Revision 0

\subsection{LIFTING AND HANDLING}

The following sections of 49 CFR pertain to the design of 1 ifting and handling features of Type A packagings:

173.411(a) Handling, securing

173.411 (b) Manual handling (gross weight 10 to $50 \mathrm{~kg}$ [22 to $110 \mathrm{lb}]$ )

173.411 (c) Mechanical handling (gross weight above $50 \mathrm{~kg}\left[\begin{array}{ll}110 \mathrm{lb} & \mathrm{b}\end{array}\right.$

173.411(d) Lifting attachments.

The exterior design of the packaging shall meet the above requirements. Analysis shall be provided to document that lifting attachments comply with 173.411(d), see Section 3.6, Design Documentation.

\subsection{TIEDOWN}

The following sections of 49 CFR pertain to the design of tie down features of Type A packagings:

173.411(a) Handling, securing

173.412(1) Tiedown, failure.

Package tie down features and equipment shall meet the above requirements.

\subsection{DESIGN DOCUMENTATION}

\subsubsection{Drawing}

A packaging general arrangement drawing which specifies the materials and components to the extent necessary to assure compliance and reliability of manufacturing of the packagings sha 17 be prepared. Any materials forming the containment boundary or related to performance shall be specified by characteristics that will ensure that the manufactured packagings will be equivalent to the prototypes used in testing or to the design qualified by evaluation.

The regulatory requirements that pertain to the content and approach of the packaging drawing are the following:

1) The packaging should be identified by a simple alpha-numeric model number. If the drawing identifies a series of packagings of similar design, a different number should be used for each to avoid confusion. 
WHC-SD-TP-RPT-017

Revision 0

2) If steel is used in the packaging, it should be specified and the specification reviewed to assure the steel is low-carbon, commercial quality steel. Stainless, open hearth, electric, basic oxygen, or other similar quality steels are acceptable.

3) If lumber is used in the packaging, it should be specified as being well seasoned, commercially dry, and free from decay, loose knots, knots that would interfere with nailing, and other defects that would materially lessen the strength.

4) If the construction process includes welding or brazing, the drawing should include guidance in order to ensure that welding or brazing are performed in a workmanlike manner using suitable and appropriate techniques, materials, and equipment.

5) Geometric tolerances in accordance with ANSI Y14.5M (ANSI, 1982) should be used whenever applicable.

6) Packaging features that are critical to the design and performance shall be dimensioned with appropriate tolerances.

7) The containment system of the packaging should be clearly specified on the drawing [49 CFR 173.462(c)].

8) External features of the packaging system should be clearly identified on the drawing so that they may be easily referenced [49 CFR 173.462(d)].

9) A number of Type A packagings use components that were specified in 49 CFR 178 (i.e., DOT-17C Steel Drum). However, HM-181 (HM-181, 1990) eliminated many of these specification packagings.

CAUTION: Packagings are now specified by particular UN performance designs (i.e., Packing Group I, Packing Group II, and Packing Group III). For this reason, designers are cautioned not to refer to such specifications in the design documentation for new packagings. New packagings should be identified in enough detail to ensure that the same packaging design will be used each time that particular packaging configuration is manufactured.

\subsubsection{Specification}

A specification for the packaging design may or may not be needed depending on its complexity. If the drawing becomes overly burdened with information, it is recommended that a specification be prepared to supplement the drawing. The specification is a useful place to state material and 
WHC-SD-TP-RPT-017

Revision 0

processing requirements for the packaging components (i.e., steel, lumber, gaskets).

\subsubsection{Analys is Report}

The following sections of 49 CFR pertain to the analysis report which documents the adequacy of the packaging:

173.411(d) Lifting attachments

173.412(d) Brittle fracture (if applicable)

173.412(7) Tiedown, failure (if applicable)

173.441 Radiation level limitations (if shielding is required)

173.442 Thermal limitations.

The following sections of 49 CFR include a chemical compatibility evaluation that documents the regulatory requirements:

173.21

173.24 (b) (3)

$173.24(\mathrm{e})(2)$

$173.24(\mathrm{e})(3)$

$173.24(f)$

$173.412(\mathrm{~g})$

$173.412(\mathrm{~h})$
Forbidden materials and packages

No mixture of gasses and vapors

No significant chemical or galvanic reaction

Plastic packagings and receptacles

Closures shall be adequate

Compatibility of packaging materials and contents

Gas generation/radiolytic decomposition/radiolysis.

The analysis report shall be of sufficient detail so that it can be verified by an independent overcheck.

\subsection{PACKAGING OPERATIONS}

\subsection{GENERAL}

The operating instructions for a packaging are the primary vehicle for the shipper to maintain control on the assembly, loading, and closure processes for a packaging and its preparation for shipment and other items. Accordingly, the applicant is requested to prepare an operating instruction for the packaging system and forward it along with the design documentation as discussed above.

\subsection{OPERATING INSTRUCTION} sections:

The operating instruction shatl consist of the following primary

- Packaging description 
WHC-SD-TP-RPT-017

Revision 0

- Authorized contents

- $\quad$ Preloading inspections

- Loading procedure

- Preparation for shipment

- Preshipment inspections

- $\quad$ Shipment requirements

- Unloading procedure

- Reuse/reconditioning (if applicable).

The packaging description and authorized contents sections shall be similar to the material for a packaging included in WHC-EP-0558, "Test and Evaluation Document for DOT Specification 7A Type A Packaging," (Cruse, 1992). The applicant shall determine the preloading inspections to be performed and the acceptance criteria considered necessary to ensure that the packaging complies with the design [49 CFR 173.474]. The loading procedure shall address al1 operations necessary to correctly assemble the packaging components, load the contents, and close the packaging. This procedure will be followed when preparing the package (with simulated contents) for testing.

The procedure addressing preparation for shipment shall meet labeling and placarding requirements (49 CFR 173.444 and 173.446) and any other applicable requirements. If the packaging must be secured to the conveyance in a particular fashion, this shall also be specified in a section to be entitled "Tiedown."

The document should be an applicant-controlied document with the number, revision, and date printed on each page.

The procedure addressing preshipment inspections shall require documentation of verifications for compliance with the following requirements:

173.441 Radiation Tevel Timitations

173.442 Thermal Timitations

173.443 Contamination control

173.474 Quality control for construction of packaging

173.475 Quality control requirements prior to each shipment of radioactive materials.

The section addressing shipment requirements shall meet the requirements and procedures applicable when the package is en route to its destination. 
WHC-SD-TP-RPT-017

Revision 0

For example, the requirements of 49 CFR 173.447 , storage incident to transportation, shall be addressed in this section.

The unloading procedure shall detail all steps necessary to safely unload the package from the conveyance and for unloading the contents from the packaging.

If the packaging may be reused, then the operating instruction shall include procedures for reconditioning the packaging to a state that will meet the design requirements, as established in the drawing and specification. The procedure shall require documented inspection of the condition of the packaging.

\subsection{PACKAGING QUALIFICATION CHECKLIST}

Appendix B contains the PQCL. Upon completion of the items discussed herein involving design documentation and operating instructions, the applicant is requested to complete the PQCL and forward it along with copies of the documentation to the DOE/HQ-approved test facility. The name and address of the test facility will be provided by the DOE when the docket is opened.

\subsection{PREPARATIONS FOR TESTING}

Upon receipt of the documentation package from the applicant, the DOE/HQ-approved test facility will review this information and resolve any comments with the applicant. Testing may begin during or after this process at the discretion of the DOE/HQ-approved test facility.

The applicant will generally be responsible for preparation of test unit packages for testing, and for delivering them to the DOE/HQ-approved test facility. For planning purposes, a minimum of two test units are usually required per package configuration to serve the testing needs. More units are normally required, the number depending on the packaging design; the $\mathrm{DOE} / \mathrm{HQ}-$ approved test facility will inform applicants of the total number of test units required as soon as possible. 


$$
\text { WHC-SD-TP-RPT-017 }
$$

Revision 0

\subsection{REFERENCES}

49 CFR, "Transportation, " Parts 100 to 177 and Parts 178 to 199, Code of Federal Regulations, as amended.

ANSI, 1982, American National Standard for Dimensioning and Tolerancing, ANSI Standard Y14.5M-(1982), American National Standards Institute, New York, New York.

Cruse, J. M., 1992, Test and Evaluation Document for DOT Specification 7A Type A Packaging, WHC-EP-0558, Revision 2, Westinghouse Hanford Company, Richland, Washington.

HM-181, 1990, Federa1 Register, Part II, Department of Transportation, Research and Special Programs Administration, Vol. 55, No. 246, Rules and Regulations, Docket No. HM-181, dated December 21, 1990.

NRC, 1984, Information Notice 84-72, dated September 10, 1984, Nuclear Regulatory Commission, Office of Inspection and Enforcement.

\subsection{GLOSSARY}

$\begin{array}{ll}\text { CFR } & \text { Code of Federal Regulations } \\ \text { DOE } & \text { U.S. Department of Energy } \\ \text { DOE-HQ } & \text { U.S. Department of Energy-Headquarters } \\ \text { DOT } & \text { U.S. Department of Transportation } \\ \text { DOT-7A } & \text { U.S. Department of Transportation Specification 7A Type A } \\ \text { EH-332 } & \text { Transportation and Packaging Safety Division (DOE-HQ) } \\ \text { HDPE } & \text { high-density polyethylene } \\ \text { ICAO } & \text { International Civil Aviation Organization } \\ \text { IE } & \text { Inspection and Enforcement } \\ \text { LSA } & \text { low specific activity } \\ \text { NRC } & \text { U.S. Nuclear Regulatory Commission } \\ \text { PQCL } & \text { Packaging Qualification CheckTist } \\ \text { STP } & \text { standard temperature and pressure } \\ \text { UN } & \text { United Nations } \\ \text { WHC } & \text { Westinghouse Hanford Company . }\end{array}$


WHC-SD-TP-RPT-017

Revision 0

APPENDIX A

TITLE 49 CODE OF FEDERAL REGULATIONS EXCERPTS 
WHC-SD-TP-RPT-017

Revision 0

\section{A.1 TITLE 49 CFR 173.24, GENERAL REQUIREMENTS FOR PACKAGINGS AND PACKAGES}

(a) Applicability. Except as otherwise provided in this subchapter, the provisions of this section apply to--

(1) Bulk and non-bulk packagings;

(2) New packagings and packagings which are reused; and

(3) Specification and non-specification packagings.

(b) Each package used for shipment of hazardous materials under this subchapter shall be designed, constructed, maintained, filled, its contents so limited, and closed so that under conditions normally incident to transportation--

(1) Except as otherwise provided in this subchapter, there will be no identifiable (without the use of instruments) release of hazardous materials to the environment;

(2) The effectiveness of the package will not be substantially reduced; for example, impact-resistance, strength, packaging compatibility, etc. must be maintained for the minimum and maximum temperatures encountered during transportation;

(3) There wi1l be no mixture of gases or vapors. in the package which could, through any credible spontaneous increase of heat or pressure, significantly reduce the effectiveness of the packaging.

(c) Authorized packagings. A packaging is authorized for a hazardous material only if--

(1) The packaging is prescribed or permitted for the hazardous material in a packaging section specified for that material in Column 8 of the section 172.101 Table and conforms to applicable requirements in the special provisions of Column 7 of the section 172.101 Table and, for specification packagings (including U.N. standard packagings), the specification requirements in parts 178 and 179 of this subchapter; or

(2) The packaging is permitted under, and conforms to, provisions contained in sections $171.11,171.12,171.12 a, 173.3,173.4,173.5$, $173.7,173.27$, or 176.11 of this subchapter.

(d) DOT specification and U.N. standard packagings. For DOT specification packagings (including U.N. standard packagings, conformance to the applicable specifications in parts 178 and 179 of this subchapter is required in all details. For performance-oriented packagings covered by subpart $L$ of part 178 of this subchapter, each packaging must be capable of meeting the performance test requirements specified in subpart M of part 178 of this subchapter for the applicable packing group shown in Column 5 of the section 172.101 Table.

(e) Compatibility.

(1) Even though certain packagings are specified in this part, it is, nevertheless, the responsibility of the person offering a hazardous material for transportation to ensure that such packagings are compatible with their lading. This particularly applies to 
WHC-SD-TP-RPT-017

Revision 0

corrosivity, permeability, softening, premature aging and embrittlement.

(2) Packaging materials and contents must be such that there will be no significant chemical or galvanic reaction between the

materials and contents of the package.

(3) Plastic packagings and receptacles.

(i) Plastic used in packagings and receptacles must be of a type compatible with the lading and may not be permeable to an extent

that a hazardous condition is likely to occur during transportation, handling or refilling.

(ii) Each plastic packaging or receptacle which is used for liquid hazardous materials must be capable of withstanding without failure the procedure specified in Appendix B of this part ("Procedure for Testing Chemical Compatibility and Rate of Permeation in Plastic Packagings and Receptacles"). The procedure specified in Appendix B of this part must be performed on each plastic packaging or receptacle used for Packing Group I materials. The maximum rate of permeation of hazardous lading through or into the plastic packaging or receptacles may not exceed 0.5 percent for materials meeting the definition of a Division 6.1 material according to section 173.132 and 2.0 percent for other hazardous materials, when subjected to temperatures no lower than--

(A) $18{ }^{\circ} \mathrm{C}\left(64{ }^{\circ} \mathrm{F}\right)$ for 180 days in accordance with Test Method 1 in Appendix $B$ of this part;

(B) $50^{\circ} \mathrm{C}\left(122^{\circ} \mathrm{F}\right)$ for 28 days in accordance with Test Method 2 in Appendix $B$ of this part; or

(C) $60^{\circ} \mathrm{C}\left(140^{\circ} \mathrm{F}\right)$ for 14 days in accordance with Test Method 3 in Appendix $B$ of this part.

(iii) Alternative procedures or rates of permeation are permitted if they yield a level of safety equivalent to or greater than that provided by paragraph (e)(3) ( $i$ i) of this section and are specifically approved by the Associate Administrator for Hazardous Materials Safety.

(4) Mixed contents. Hazardous materials may not be packed or mixed together in the same outer packaging with other hazardous or nonhazardous materials if such materials are capable of reacting dangerously with each other and causing--

(i) Combustion or dangerous evolution of heat;

(ii) Evolution of flammable or poisonous gases; or

(iii) Formation of unstable or corrosive materials.

(5) Packagings used for solids, which may become 1 iquid at temperatures likely to be encountered during transportation, must be capable of containing the hazardous material in the liquid state.

(f) Closures.

(1) Closures on packagings shall be so designed and closed that under conditions (including the effects of temperature and vibration) normally incident to transportation-- 
WHC-SD-TP-RPT-017

Revision 0

(i) Except as provided in paragraph (g) of this section, there is no identifiable release of hazardous materials to the environment from the opening to which the closure is applied; and

(ii) The closure is secure and leakproof.

(2) Except as otherwise provided in this subchapter, a closure (including gaskets or other closure components, if any) used on a specification packaging must conform to all applicable requirements of the specification.

(g) Venting. Venting of packagings, to reduce internal pressure which may develop by the evolution of gas from the contents, is permitted only when--

(1) Transportation by aircraft is not involved;

(2) Except as otherwise provided in this subchapter, the evolved gases are not poisonous, likely to create a flammable mixture with

air or be an asphyxiant under normal conditions of transportation;

(3) The packaging is designed so as to preciude an unintentional

release of hazardous materials from the receptacle; and

(4) For shipments in bulk packagings, venting is authorized for the specific hazardous material by a special provision in the section 172.101 Table or by the applicable bulk packaging specification in part 178 of this subchapter.

(h) Outage and filling limits--

(1) General. When filling packagings and receptacles for liquids, sufficient uilage (outage) must be left to ensure that neither

leakage nor permanent distortion of the packaging or receptacle will occur as a result of an expansion of the liquid caused by temperatures likely to be encountered during transportation. Requirements for outage and filling limits for non-bulk and bulk packaging are specified in section $173.24 \mathrm{a}(\mathrm{d})$ and $173.24 \mathrm{~b}(\mathrm{a})$, respectively.

(2) Compressed gases and cryogenic liquids. Filling limits for compressed gases and cryogenic liquids are specified in sections 173.301 through 173.306 for cylinders and sections 173.314 through 173.319 for bulk packagings.

(i) Air transportation. Packages offered or intended for transportation by aircraft must conform to the general requirements for transportation by aircraft in section 171.11 of this subchapter. 
WHC-SD-TP-RPT-017

Revision 0

\section{A.2 TITLE 49 CFR 173.24a, ADDITIONAL GENERAL REQUIREMENTS FOR NON-BULK PACKAGINGS AND PACKAGES}

(a) Packaging design. Except as provided in section 172.312 of this subchapter:

(1) Inner packaging closures. A combination packaging containing liquid hazardous materials must be packed so that closures on inner packagings are upright.

(2) Friction. The nature and thickness of the outer packaging must be such that friction during transportation is not likely to generate and amount of heat sufficient to alter dangerousiy the chemical stability of the contents.

(3) Securing and cushioning. Inner packagings of combination packagings must be so packed, secured and cushioned to prevent their breakage or leakage and to control their movement within the outer packaging under conditions normally incident to transportation. Cushioning material must not be capable of reacting dangerously with the contents of the inner packagings.

(4) Metallic devices. Nails, staples and other metallic devices shall not protrude into the interior of the outer packaging in such a manner as to be likely to damage inner packagings or receptacles. (5) Vibration. Each non-bulk package must be capable of withstanding, without rupture or leakage, the vibration test procedure specified in section 178.608 of this subchapter.

(b) Non-bulk packaging filling limits.

(1) A single or composite non-bulk packaging may be filled with a liquid hazardous material only when the specific gravity of the material does not exceed that marked on the packaging, or a specific gravity of 1.2 if not marked, except as follows:

(i) A Packing Group I packaging may be used for a Packing Group II material with a specific gravity not exceeding the greater of 1.8 , or 1.5 times the specific gravity marked on the packaging, provided all the performance criteria can still be met with the higher specific gravity material;

(ii) A Packing Group I packaging may be used for a Packing Group III material with a specific gravity not exceeding the greater of 2.7 , or 2.25 times the specific gravity marked on the packaging, provided all the performance criteria can still be met with the higher specific gravity material; and

(iii) A Packing Group II packaging may be used for a Packing Group III material with a specific gravity not exceeding the greater of 1.8 , or 1.5 times the specific gravity marked on the packaging, provided all the performance criteria can still be met with the higher specific gravity material.

(2) Except as other wise provided in this section, a single or composite non-bulk packaging may not be filled with a solid 
WHC-SD-TP-RPT-017

Revision 0

hazardous material to a gross mass greater than the maximum gross mass marked on the packaging.

(3) A single or composite non-bulk packaging which is tested and marked for liquid hazardous materials may be filled with a solid hazardous material to a gross mass, in kilograms, not exceeding the rated capacity of the packaging in liters, multiplied by the specific gravity marked on the packaging, or 1.2 if not marked. In addition:

(i) A single or composite non-bulk packaging which is tested and marked for Packing Group I liquid hazardous materials may be filled with a solid Packing Group II hazardous material to a gross mass, in kilograms, not exceeding the rated capacity of the packaging in liters, multiplied by 1.5, multiplied by the specific gravity marked on the packaging, or 1.2 if not marked.

(ii) A single or composite non-bulk packaging which is tested and marked for Packing Group I liquid hazardous materials may be filled with a solid Packing Group III hazardous material to a gross mass, in kilograms, not exceeding the rated capacity of the packaging in 7 iters, multiplied by 2.25 , multiplied by the specific gravity marked on the packaging, or 1.2 if not marked.

(iii) A single or composite non-bulk packaging which is tested and marked for Packing Group II liquid hazardous materials may be filled with a solid Packing Group III hazardous material to a gross mass, in kilograms, not exceeding the rated capacity of the packaging in 7iters, multiplied by 1.5, multiplied by the specific gravity marked on the packaging, of 1.2 if not marked.

(4) Packagings tested as prescribed in section 178.605 of this subchapter and marked with the hydrostatic test pressure as prescribed in section 178.503(a)(5) of this subchapter may be used for liquids only when the vapor pressure of the liquid conforms to one of the following:

(i) The vapor pressure must be such that the total pressure in the packaging [i.e., the vapor pressure of the liquid plus the partial pressure of air or other inert gases, less $100 \mathrm{kPa}(15 \mathrm{psi})$ at $55{ }^{\circ} \mathrm{C}$ $\left(131^{\circ} \mathrm{F}\right)$, determined on the basis of a maximum degree of filling in accordance with paragraph (b) (1) of this section and a filling temperature of $\left.15{ }^{\circ} \mathrm{C}\left(59^{\circ} \mathrm{F}\right)\right]$, will not exceed two-thirds of the marked test pressure;

(ii) The vapor pressure at $50^{\circ} \mathrm{C}\left(122{ }^{\circ} \mathrm{F}\right)$ must be less than foursevenths of the sum of the marked test pressure plus $100 \mathrm{kPa}$ (15 psi); or

(iii) The vapor pressure at $55^{\circ} \mathrm{C}\left(131{ }^{\circ} \mathrm{F}\right)$ must be less than twothirds of the sum of the marked test pressure plus $100 \mathrm{kPa}$ (15 psi). (5) No hazardous material may remain on the outside of a package after filling.

(c) Mixed contents.

(1) An outer non-bulk packaging may contain more than one hazardous material only when-- 


$$
\text { WHC-SD-TP-RPT-017 }
$$

Revision 0

(i) The inner and outer packagings used for each hazardous material conform to the relevant packaging sections of this part applicable to that hazardous material;

(ii) The package as prepared for shipment meets the performance tests prescribed in part 178 of this subchapter for the packing group indicating the highest order of hazard for the hazardous materials contained in the package;

(iii) Corrosive materials (except ORM-D) in bottles are further packed in securely closed inner receptacles before packing in outer packagings; and

(iv) For transportation by aircraft, the total net quantity does not exceed the lowest permitted maximum net quantity per package as shown in Column 9a or 9b, as appropriate, of the section 172.101 Table. The permitted maximum net quantity must be calculated in kilograms if a package contains both a liquid and a solid.

(2) A packaging containing inner packagings of Division 6.2 materials may not contain other hazardous materials, except dry ice. (d) Liquids must not completely fill a receptacle at a temperature of $55^{\circ} \mathrm{C}\left(131^{\circ} \mathrm{F}\right)$ or Tess. 
WHC-SD-TP-RPT-017

Revision 0

\section{A.3 TITLE 49 CFR 173.24b, ADDITIONAL GENERAL REQUIREMENTS FOR BULK PACKAGINGS}

(a) Outage and filling limits.

(1) Liquids and liquefied gases must be so loaded that the outage is at least one percent of the total capacity of a cargo or portable tank, or compartment thereof, or at least one percent of the total capacity of the tank and dome for tank car and multi-unit tank car tanks at the reference temperature of $46^{\circ}{ }^{\circ} \mathrm{C}\left(115^{\circ} \mathrm{F}\right)$ for uninsulated tanks and $41{ }^{\circ} \mathrm{C}\left(105^{\circ} \mathrm{F}\right)$ for insulated tanks.

(2) Hazardous materials may not be loaded into the dome of a tank car. If the dome of the tank car does not provide sufficient outage, vacant space must be left in the shell to provide the required outage.

(3) Bulk packagings for materials poisonous by inhalation. For a material which meets the definition of poisonous by inhalation (see section 178.1 of this subchapter), the outage in a bulk packaging must be at least fiver percent of the total capacity of the tank or compartment at the reference temperature of $46{ }^{\circ} \mathrm{C}\left(115^{\circ} \mathrm{F}\right)$ for uninsulated tanks and $41{ }^{\circ} \mathrm{C}\left(105^{\circ} \mathrm{F}\right)$ for insulated tanks.

(b) Equivalent stee7. For the purposes of this section, stainless steel is steel with a guaranteed minimum tensile strength of 51.7 deka newtons per square millimeter $(75,000 \mathrm{psi})$ and a guaranteed elongation of 40 percent or greater. Where the regulations permit steel other than stainless steel to be used in place of a specified stainless steel (for example, as in section 172.102 of this subchapter, special provision B30), the minimum thickness for the steel must be obtained from one of the following formulas, as appropriate:

Formula for metric units:

$e_{1}=\left(12.74 e_{0}\right) /\left(R m_{1} A_{1}\right)^{1 / 3}$

Formula for non-metric units:

$e_{1}=\left(144.2 e_{0}\right) /\left(\mathrm{Rm}_{1} \mathrm{~A}_{1}\right)^{1 / 3}$

Where:

$e_{0}=$ Required thickness of the reference stainless steel in millimeters or inches respectively;

$e_{1}=$ Equivalent thickness of the steel used in millimeters or inches respectively;

$\mathrm{Rm}_{\mathrm{m}}=$ Specified minimum tensile strength of the steel used in deka newtons per square millimeter or pounds per square inch respectively; and

$A_{1}=$ Specified minimum percentage elongation of the steel used multiplied by 100 (for example, 20 percent times 100 equals 20 ). Elongation values used must be determined from a $50 \mathrm{~mm}$ or 2 inch test specimen. 
WHC-SD-TP-RPT-017

Revision 0

(c) Air pressure in excess of ambient atmospheric pressure may not be used to load or unload any lading which may create an air-enriched

mixture within the flammability range of the lading in the vapor space of the tank.

(d) A bulk packaging may not be loaded with a hazardous material that:

(1) Is at a temperature outside of the packaging's design temperature range; or

(2) Exceeds the maximum weight of lading marked on the specification plate. 
WHC-SD-TP-RPT-017

Revision 0

\section{A.4 TITLE 49 CFR 173.411, GENERAL DESIGN REQUIREMENTS}

Except for a package that contains a limited quantity or excepted instrument or article under sections 173.421 through 173.424, each package used for shipment of radioactive materials shall be designed so that:

(a) The package can be easily handled and properly secured in or on a conveyance during transport;

(b) A package with a gross weight exceeding 10 kilograms (22 pounds) and up to 50 kilograms ( 110 pounds) has a means for manual handling;

(c) A package with a gross weight of 50 kilograms (110 pounds) or more can be safely handled by mechanical means;

(d) Each lifting attachment on the package, when used in the intended manner, with a minimum safety factor of three, does not impose an unsafe stress on the structure of the package. In addition, the lifting attachment shall be so designed that failure under excessive load would not impair the ability of the package to meet all other requirements of this subpart. Each attachment or other feature on the outer surface of the packaging that could be used to lift the package must be removable or otherwise capable of being made inoperable for transport, or shall be designed with strength equivalent to that required for lifting attachments;

(e) The external surface, as far as practicable, may be easily decontaminated;

(f) The outer layer of packaging will avoid, as far as practicable, pockets or crevices where water might collect; and

(g) Each feature that is added to the package at the time of transport, and that is not a part of the package, will not reduce the safety of the package. 
WHC-SD-TP-RPT-017

Revision 0

\section{A.5 TITLE 49 CFR 173.412, ADDITIONAL DESIGN REQUIREMENTS FOR TYPE A PACKAGES}

In addition to meeting the general design requirements prescribed in section 173.411, each Type A packaging shal1 be designed so that:

(a) The smallest overall external dimension of the package is not less than 10 centimeters (4 inches);

(b) The outside of the packaging incorporates a feature, such as a seal; that is not readily breakable, and that, while intact, is evidence that the package has not been opened. In the case of packages shipped in exclusive use closed transport vehicles, the cargo compartment may be sealed instead of the individual packages;

(c) As far as practicable, the external surfaces are free from protrusions and are designed and finished so that they can be easily decontaminated;

(d) Containment and shielding would be maintained during transportation and storage in a temperature range of $-40{ }^{\circ} \mathrm{C}\left(-40^{\circ} \mathrm{F}\right)$ to $70^{\circ} \mathrm{C}\left(158^{\circ} \mathrm{F}\right)$ with account being taken of the possibility of brittle fracture;

(e) It is able to withstand the effects of any acceleration, vibration, or vibration resonance that may arise during normal transportation, without any deterioration of the effectiveness of closing devices or of the integrity of the package as a whole and without loosening or unintentional release of nuts, bolts, or other securing devices even after repeated use;

(f) It includes a containment system securely ciosed by a positive fastening device that cannot be opened unintentionally or by pressure that may arise within the package during normal transport. Special form, as demonstrated in accordance with section 173.469 may be considered as a component of the containment system;

(g) The materials of the packaging and any components or structures are physically and chemically compatible with each other and with the contents, taking into account the behavior of each under irradiation; (h) For each component of the containment system account is taken, where applicable, or radiolytic decomposition of materials and the generation of gas by chemical reaction and radiolysis;

(i) The containment system wil1 retain its radioactive contents under the reduction of ambient pressure to .25 kilograms per square centimeter ( 3.5 pounds per square inch);

(j) Each valve through which the radioactive contents could otherwise escape is protected against damage and unauthorized operation and, except for a pressure relief device, has an enclosure to retain any leakage;

(k) Any radiation shield that encloses a component of the packaging specified as part of the containment system will prevent the unintentional escape of that component from the shield;

(1) Failure of any tie down attachment of the packaging under excessive load will not impair the ability of the package to meet other requirements of this subpart; 
WHC-SD-TP-RPT-017

Revision 0

(m) When subjected to the tests specified in section 173.465 or evaluated against these tests by any of the methods authorized by section 173.461(a), the packaging will prevent:

(1) Loss or dispersal of the radioactive contents; and

(2) Any significant increase in the radiation levels recorded or calculated at the external surfaces for the condition before the test;

(n) Each packaging designed for Tiquids will:

(1) Meet the conditions prescribed in paragraph (m) of this section when subjected to the tests specified in section 173.466 or evaluated against these tests by any of the methods authorized by section 173.461(a);

(2) For any package with a liquid volume not exceeding 50 cubic centimeters (1.7 fluid ounces), have sufficient suitable absorbent material to absorb twice the volume of the liquid contents. The absorbent material shall be compatible with the package contents and suitably positioned to contact the liquid in the event of leakage; and

(3) For any package with a liquid volume exceeding 50 cubic centimeters ( 1.7 fluid ounces), either:

(i) Have sufficient absorbent material as prescribed in paragraph (n) (2) of this section; or

(ii) Have a containment system composed of primary inner and secondary outer containment components designed to assure retention of the liquid contents within the secondary outer components in the event that the primary inner components leak; and

(0) Each package designed for compressed or uncompressed gases other than tritium or argon-37 not exceeding 200 curies will be able to prevent loss of contents when the package is subjected to the tests prescribed in section 173.466 or evaluated against these tests by any of the methods authorized by section 173.461(a). 
WHC-SD-TP-RPT-017

Revision 0

\section{A.6 TITLE 49 CFR 173.462, PREPARATION OF SPECIMENS FOR TESTING}

(a) Each specimen (i.e., sample, prototype or scale model) shall be examined before testing to identify and record faults or damage, including:

(1) Divergence from the specifications or drawings;

(2) Defects in construction;

(3) Corrosion or other deterioration; and

(4) Distortion of features.

(b) Any deviation found under paragraph (a) of this section from the specified design shall be corrected or suitably taken into account in the subsequent evaluation.

(c) The containment system of the packaging shall be clearly specified.

(d) The external features of the specimen shall be clearly identified so that reference may be made to any part of it. 
WHC-SD-TP-RPT-017

Revision 0

\section{A.7 TITLE 49 CFR 178.3, MARKING OF PACKAGINGS}

(a) Each packaging manufactured to a DOT specification or a UN Standard shall be marked as follows:

(1) In an unobstructed area, with letters, and numerals identifying the standards or specification (e.g., UN IA1, DOT 4B240ET, etc.). (2) Unless otherwise specified in this part, with the name and address or symbol of the manufacturer, or, for a UN standard packaging, the approval agency certifying compliance with the UN standard. Symbols, if used, must be registered with the Associate Administrator for Hazardous Materials Safety. Duplicative symbols are not authorized.

(3) The markings must be stamped, embossed, burned, printed or otherwise marked on the packaging to provide adequate accessibility, permanency, contrast, and legibility so as to be readily apparent and understood.

(4) Unless otherwise specified, letters and numerals must be at least $12.0 \mathrm{~mm}$ ( 0.47 inches) in height except that for packagings of less than or equal to $30 \mathrm{~L}$ ( 7.9 gallons) capacity for 1 iquids or $30 \mathrm{~kg}$ (66 pounds) capacity for solids the height must be at least $6.0 \mathrm{~mm}$ ( 0.2 inches).

(b) Packagings may be marked with the United Nations symbol and packaging identification code as provided in this subchapter, in the ICAO Technical Instructions or in Annex 1 to the IMDG Code, provided the person applying these marks has established that the packaging conforms to the applicable provisions of this subchapter, the ICAO Technical Instructions or Annex 1 to the IMDG Code, respectively.

(1) If an indication of the State in whose territory the specified tests are carried out, or of the Stat authorizing the allocation of the mark, is required by this part (see section 178.503 of this part), the letters "USA" shall be used if the manufacturing and testing occurs in the United States.

(2). If an indication of the name of the manufacturer or other identification of the packaging as specified by the competent authority is required, the name and address or symbol of the person making the mark shall be entered. Symbols, if used, must be registered with the Associate Administrator for hazardous Materials Safety. Duplicate symbols are not authorized.

(3) Packagings manufactured to UN standards in accordance with this subchapter sha7l be marked as prescribed in section 178.503 of this part.

(c) Where a packaging conforms to more than one UN standard or DOT specification, the packaging may bear more than one marking, provided the packaging meets all the requirements of each standard or specification. Where more than one marking appears on a packaging, each marking must appear in its entirety. 


$$
\begin{gathered}
\text { WHC-SD-TP-RPT-017 } \\
\text { Revision } 0
\end{gathered}
$$

\title{
ALSO SEE:
}

\author{
173.415(a) Authorized Type A Packages \\ 173.442 Thermal Limitations \\ 173.461 Demonstration of Compliance with Tests \\ 173.463 Packaging and Shielding - Testing for Integrity \\ 173.465 Type A Packaging Tests \\ 173.466 Additional Tests for Type A Packagings Designed for Liquids \\ and Gases \\ 173.474 Quality Control for Construction of Packaging \\ 173.475 Quality Control Requirements Prior to Each Shipment of \\ Radioactive Material \\ 178.350 Specification 7A; General Packaging, Type A.
}

NOTE: In section $178.350-3$, marking requirements reference back to section 173.24. These marking requirements were actually moved to section 178.3 per the HM-181 guidelines; however, a typographical error current1y exists as 49 CFR does not call out section 178.3 where specific reference to marking requirements is located. 
WHC-SD-TP-RPT-017

Revision 0

\section{APPENDIX B}

DOT-7A TYPE A

PACKAGING QUALIFICATION CHECKLIST

B-1 
When subjected to the tests specified in 49 CFR 173.465 (and 173.466 when applicable) or evaluated against these tests by any of the methods authorized by 49 CFR 173.461(a), the packaging will prevent:

(1) Loss or dispersal of the radioactive contents; and

(2) Any significant increase in the radiation levels recorded or

calculated at the external surfaces for the condition before the test.

\subsection{Characterization of Contents}

\section{Radiological}

Limited to Type A Quantity of Radionuclides

Isotopic Inventory:

\begin{tabular}{||c|c|c|c|c||}
\hline \multirow{2}{*}{ RADIONUCLIDES } & \multicolumn{3}{|c||}{ QUANTITY (per package) } & DECAY HEAT \\
\hline & curies & Grams & $\begin{array}{c}\text { Grams } \\
\text { Fissile }\end{array}$ & Hatts/gram \\
\hline & & & & \\
\hline & & & & \\
\hline & & & & \\
\hline & & & & \\
\hline
\end{tabular}

(Use extra sheets if needed.)
Fissile Class:
[ ]-Exempt
[ ]-I
[ ]-II
[ ]-III

Physical

Form Category:

[ ] Norma1

[ ] Special (see 49 CFR 173.469)

Physical Form:

[ ] Solid

[ ] Form 1 [ ] Form 2 [ ] Form 3

Density: $\left(\mathrm{kg} / \mathrm{m}^{3}\right)$

[ ] Liquid Specific gravity: Viscosity:

[ ] Gas

Volume: $\left(\mathrm{cm}^{3}\right.$ at STP)

Thermal

Total wattage of contents: (watts/package) 
DOT-7A TYPE A

PACKAGING QUALIFICATION CHECKLIST

\subsection{Characterization of Contents (continued)}

\section{Chemical}

Non-Radioactive Constituents:

\begin{tabular}{|c|c|c|c|c|}
\hline \multirow[t]{2}{*}{ PROPER SHIPPING NAME } & \multirow{2}{*}{$\begin{array}{c}\text { IDENTIFICATION } \\
\text { NUMBER } \\
:\end{array}$} & \multicolumn{3}{|c|}{$\begin{array}{l}\text { EXPECTED QUANTITY } \\
\text { (per package) }\end{array}$} \\
\hline & & $\begin{array}{c}\text { Solids } \\
\text { (grams) } \\
\end{array}$ & $\begin{array}{c}\text { Liquids } \\
\text { (ml) } \\
\end{array}$ & $\left(\mathrm{cm}^{3}{ }^{\text {Gases }}\right.$ at STP $)$ \\
\hline & & & & \\
\hline & & & & \\
\hline & & & & \\
\hline & & & & \\
\hline & & & & \\
\hline & & & & \\
\hline & & & & \\
\hline & & & & \\
\hline & & & & \\
\hline & & & & \\
\hline & & & & \\
\hline & & & & \\
\hline & & & & \\
\hline & & & & \\
\hline & & & & \\
\hline
\end{tabular}

(Use extra sheets if needed.) 


\subsection{CFR 173.24 General requirements for packagings and packages.}

\subsection{4 (a) Applicability.}

Except as otherwise provided in this subchapter, the provisions of this section apply to--

(1) Bulk and non-bulk packagings;

(2) New packagings and packagings which are reused; and

(3) Specification and non-specification packagings.

This requirement applies. Please indicate the following.

Addressed in:

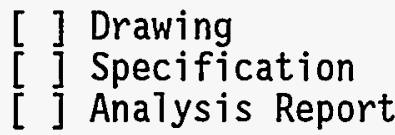

[ ] Operating Instruction
[ ] Manufacturer Supplied Data
[ ] Similarity or Documented Record

Specify:

\subsection{4 (b) Containment.}

Each package used for the shipment of hazardous materials under this subchapter shall be designed, constructed, maintained, filled, its contents so limited, and closed, so that under conditions normally incident to transportation--

(1) Except as otherwise provided in this subchapter, there will be no identifiable (without the use of instruments) release of hazardous materials to the environment;

(2) The effectiveness of the package will not be substantially reduced; for example, impact resistance, strength, packaging compatibility, etc. must be maintained for the minimum and maximum temperatures encountered during transportation;

(3) There will be no mixture of gases or vapors in the package which could, through any credible spontaneous increase of heat or pressure, significantly reduce the effectiveness of the packaging.

This requirement: [ ] Does not apply.

[ ] Applies; indicate the following.

Addressed in:
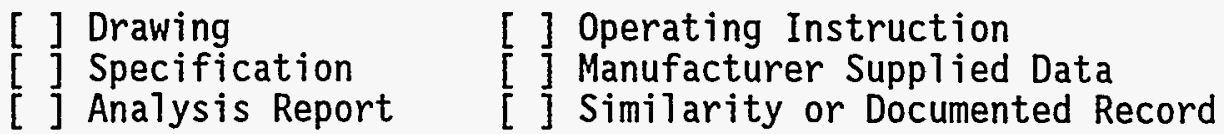

Specify: 


\subsection{4 (c) Authorized Packagings.}

A packaging is authorized for a hazardous material only if--

(1) The packaging is prescribed or permitted for the hazardous material in a packaging section specified for that material in Column 8 of the section 172.101 Table and conforms to applicable requirements in the special provisions of column 7 of the section 172.101 Table and, for specification packagings (including U.N. standard packagings), the specification requirements in parts 178 and 179 of this subchapter; or

(2) The packaging is permitted under, and conforms to, provisions contained in sections $171.11,171.12,171.12 a, 173.3,173.4,173.5,173.7,173.27$ or 176.11 of this subchapter.

This requirement: [ ] Does not apply.

Addressed in:
[ ] Applies; indicate the following.

[ ] Operating Instruction

[ ] Manufacturer Supplied Data

[ ] Similarity or Documented Record

Specify:

\subsection{4 (d) DOT Specification and U.N. Standard Packagings.}

DOT specification and U.N. standard packagings. For DOT specification packagings (including U.N. standard packagings), conformance to the applicable specifications in parts 178 and 179 of this subchapter is required in all details. For performance-oriented packagings covered by subpart $L$ of part 178 of this subchapter, each packaging must be capable of meeting the performance test

requirements specified in subpart $M$ of part 178 of this subchapter for the applicable packing group shown in column 5 of the section 172.101 Table.

This requirement: [ ] Does not apply. [ ] Applies; indicate the following.

Addressed in: [ ] Drawing [ ] Operating Instruction

[ ] Specification

[ ] Analysis Report

[ ] Operating Instruction

[ ] Similarity or Documented Record

Specify: 
DOT-7A TYPE A

PACKAGING QUALIFICATION CHECKLIST

\subsection{4 (e) Compatibility.}

(1) Even though certain packagings are specified in this part, it is, nevertheless, the responsibility of the person offering a hazardous material for transportation to ensure that such packagings are compatible with their lading. This particularly applies to corrosivity, permeability, softening, premature aging and embrittlement.

(2) Packaging materials and contents must be such that there will be no significant chemical or galvanic reaction between the materials and contents of the package.

This requirement: [ ] Does not apply. [ ] Applies; indicate the following.

Addressed in:

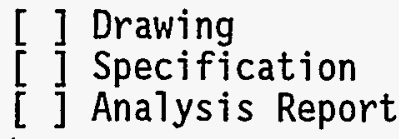

[ ] Operating Instruction

[ ] Manufacturer Supplied Data ] Similarity or Documented Record

Specify:

(3) Plastic packagings and receptacles.

(i) Plastic used in packagings and receptacles must be of a type compatible with the lading and may not be permeable to an extent that a hazardous condition is likely to occur during transportation, handling or refilling.

(ii) Each plastic packaging or receptacle which is used for liquid hazardous materials must be capable of withstanding without failure the procedure specified in appendix $B$ of this part ("Procedure for Testing Chemical Compatibility and Rate Permeation in Plastic Packagings and Receptacles")...

This requirement: [ ] Does not apply. [ ] Applies; indicate the following.
Addressed in:
[] Drawing
$[$ ] Specification
[ ] Analysis Report
[ ] Operating Instruction
[ ] Manufacturer Supplied Data
[ ] Similarity or Documented Record

Specify: 


\subsection{4 (e) Compatibility. (Continued)}

... (4) Mixed contents. Hazardous materials may not be packed or mixed together in the same outer packaging with other hazardous or nonhazardous materials if such materials are capable of reacting dangerously with each other and causing--

(i) Combustion or dangerous evolution of heat;

(ii) Evolution of flamable or poisonous gases; or

(iii) Formation of unstable or corrosive materials.

(5) Packagings used for solids, which may become liquid at temperatures likely to be encountered during transportation, must be capable of containing the hazardous material in the liquid state.

This requirement: [ ] Does not apply.

[ ] Applies; indicate the following.

Addressed in:

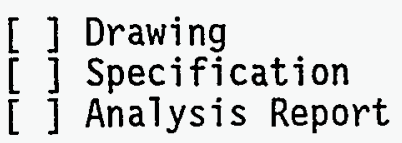
[ ] Operating Instruction Manufacturer Supplied Data [ Similarity or Documented Record

Specify:

\subsection{4 (f) Closures.}

(1) Closures on packagings shall be so designed and closed that under conditions (including the effects of temperature and vibration) normally incident to transportation-

(i) Except as provided in paragraph (g) of this section, there is no identifiable release of hazardous materials to the environment from the opening to which the closure is applied; and

(ii) The closure is secure and leakproof.

(2) Except as otherwise provided in this subchapter, a closure (including gaskets or other closure components, if any) used on a specification packaging must conform to all applicable requirements of the specification.

This requirement: [ ] Does not apply. Addressed in: Drawing Specification Analys is Report
[ ] Applies; indicate the following.

[ ] Operating Instruction [ ] Manufacturer Supplied Data Similarity or Documented Record

Specify: 


\subsection{4 (g) Venting.}

Venting of packagings, to reduce internal pressure which may develop by the evolution of gas from the contents, is permitted only when--

(1) Transportation by aircraft is not involved;

(2) Except as otherwise provided in this subchapter, the evolved gases are not poisonous,

likely to create a flamable mixture with air or be an asphyxiant under normal conditions of transportation;

(3) The packaging is designed so as to preclude an unintentional release of hazardous materials from the receptacle; and

(4) For shipments in bulk packagings, venting is authorized for the specific hazardous material by a special provision in the section 172.101 Table or by the applicable bulk packaging specification in part 178 of this subchapter.

This requirement: [ ] Does not apply.

Addressed in:
[ ] Applies; indicate the following.

[ ] Operating Instruction

[ ] Manufacturer Supplied Data

[ ] Similarity or Documented Record

Specify:

\subsection{4 (h) Outage and Filling Limits.}

(1) General. When filling packagings and receptacles for liquids, sufficient ullage (outage) must be left to ensure that nejther leakage nor permanent distortion of the packaging or receptacle will occur as a resutt of an expansion of the liquid caused by temperatures likely to be encountered during transportation. Requirements for outage and filling limits for nonbulk and bulk packagings are specified in sections $173.24 \mathrm{a}(\mathrm{d})$ and $173.24 \mathrm{~b}(\mathrm{a})$, respectively. (2) Compressed gases and cryogenic liquids. Filling timits for compressed gases and cryogenic liquids are specified in sections 173.301 through 173.306 for cylinders and sections 173.314 through 173.319 for bulk packagings.

This requirement: [ ] Does not apply.

Addressed in:

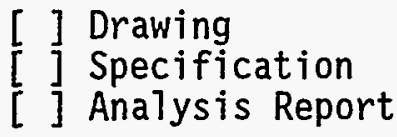

[ ] Applies; indicate the following.

[ ] Operating Instruction

[ ] Manufacturer Supplied Data

[ ] Similarity or Documented Record

Specify: 


\section{Revision 0}

DOT-7A TYPE A

PACKAGING QUALIFICATION CHECKLIST

\subsection{4 (i) Air Transportation.}

Packages offered or intended for transportation by aircraft must conform to the general requirements for transportation by aircraft in section 173.27 except as provided in section 171.11 of this subchapter.

This requirement: [ ] Does not apply. [ ] Applies; indicate the following. Addressed in:
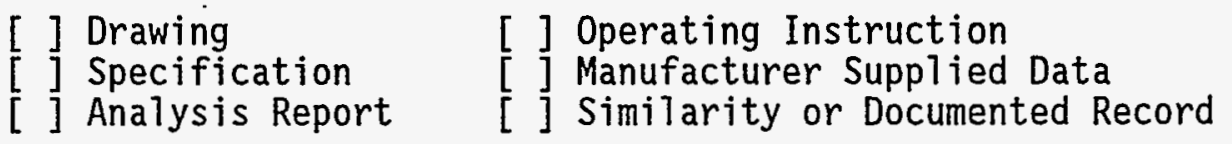

Specify: 


\subsection{9 CFR 173.24a Additional general requirements for non-bulk packagings and packages.}

\subsection{4a (a) Packaging Design.}

Except as provided in section 172.312 of this subchapter:

(1) Inner packaging closures. A combination packaging containing liquid hazardous materials

must be packed so that closures on inner packagings are upright.

(2) Friction. The nature and thickness of the outer packaging must be such that friction during transportation is not likely to generate an amount of heat sufficient to alter dangerously the chemical stability of the contents.

(3) Securing and cushioning. Inner packagings of combination packagings must be so packed, secured and cushioned to prevent their breakage or leakage and to control their movement within the outer packaging under conditions normally incident to transportation. Cushioning material must not be capable of reacting dangerously with the contents of the inner packagings.

(4) Metallic devices. Nails, staples and other metallic devices shall not protrude into the interior of the outer packaging in such a manner as to be likely to damage inner packagings or receptacles.

This requirement: [ ] Does not apply.

[ ] Applies; indicate the following.

Addressed in:
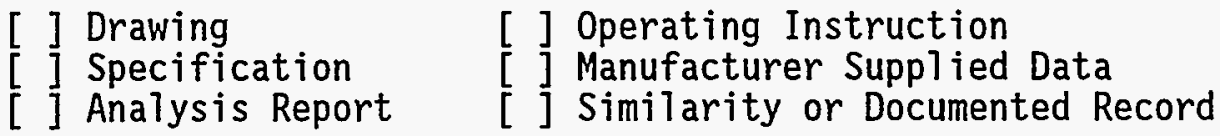

Specify:

\subsection{4a (a) Packaging Design. (Continued)}

(5) Vibration. Each non-bulk package must be capable of withstanding, without rupture or leakage, the vibration test procedure specified in section 178.608 of this subchapter.

This requirement: [ ] Does not apply. [ ] Applies; indicate the following.

Addressed in:

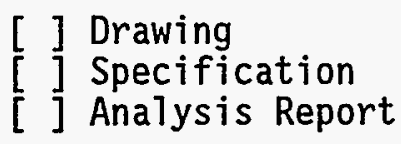

[ ] Operating Instruction

[ ] Manufacturer Supplied Data

[ ] Similarity or Documented Record

Specify: 


\subsection{4a (b) Non-bulk Packaging Filling Limits.}

(1) A single or composite non-bulk packaging may be filled with a liquid hazardous material only when the specific gravity of the material does not exceed that marked on the packaging, or a specific gravity of 9.2 if not marked...

... (2) Except as otherwise provided in this section, a single or composite non-bulk packaging may not be filled with a solid hazardous material to a gross mass greater than the maximum gross mass marked on the packaging.

(3) A single or composite non-bulk packaging which is tested or marked for liquid hazardous materials may be filled with a solid hazardous material to a gross mass, in kilograms, not exceeding the rated capacity of the packaging in liters, multiplied by the specific gravity marked on the packaging, or 1.2 if not marked...

... (5) No hazardous material may remain on the outside of a package after filling. NOTE: TYPe A limits are identified in 49 CFR 173.443.
This requirement: [ ] Does not apply.
[ ] Applies; indicate the following.
Addressed in:
[ ] Drawing
[ ] Specification
[ Analysis Report
[ ] Operating Instruction
[ ] Manufacturer Supplied Data
[ ] Similarity or Documented Record

Specify: 


\section{$173.24 \mathrm{a}$ (c) Mixed Contents.}

(1) An outer non-bulk packaging may contain more than one hazardous material only when-(i) The inner and outer packagings used for each hazardous material conform to the relevant packaging sections of this part applicable to that hazardous material;

(ii) The package as prepared for shipment meets the performance tests prescribed in part 178 of this subchapter for the packing group indicating the highest order of hazard for the hazardous materials contained in the package.

(iii) Corrosive materials (except $O R M-D$ ) in bottles are further packed in securely closed inner receptacles before packing in outer packagings; and

(iv) For transportation by aircraft, the total net quantity does not exceed the lowest permitted maximum net quantity per package as shown in Colum $9 a$ or $9 b$, as appropriate, of the section 172.101 Table. The permitted maximum net quantity must be calculated in ki lograms if a package contains both a liquid and a solid.

(2) A packaging containing inner packagings of Division 6.2 materials may not contain other hazardous materials, except dry ice.

This requirement: [ ] Does not apply. - Addressed in: [ ] Drawing
$[$ ] Specification
[ ] Analysis Report
[ ] Applies; indicate the following.

[ ] Operating Instruction

[ ] Manufacturer Supplied Data

[ ] Similarity or Documented Record

Specify:

\subsection{4a (d) Liquid Fill Level.}

Liquids must not completely fill a receptacle at a temperature of $55^{\circ} \mathrm{C}\left(131^{\circ} \mathrm{F}\right)$ or less.

This requirement: [ ] Does not apply. [ ] Applies; indicate the following. Addressed in:

[ ] Drawing
[ ] Specification
[ Analysis Report

[ ] Operating Instruction

[ ] Manufacturer Supplied Data

[ ] Similarity or Documented Record

Specify: 
DOT-7A TYPE A

PACKAGING QUALIFICATION CHECKLIST

\subsection{CFR 173.24b Additional general requirements for bulk packagings.}

\subsection{4b (a) Outage and Filling Limits.}

(1) Liquids and liquified gases must be so loaded that the outage is at least one percent of the total capacity of a cargo or portable tank, or compartment thereof, or at least one percent of the total capacity of the tank and dome for tank car and multi-unit tank car tanks at the reference temperature of $46^{\circ} \mathrm{C}\left(115^{\circ} \mathrm{F}\right.$ ) for uninsulated tanks and $41{ }^{\circ} \mathrm{C}\left(105^{\circ} \mathrm{F}\right)$ for insulated tanks.

(2) Hazardous materials may not be loaded into the dome of a tank car. If the dome of a tank car does not provide sufficient outage, vacant space must be left in the shell to provide the required outage.

(3) Bulk packagings for materials poisonous by inhalation. For a material which meets the definition of poisonous by inhalation (see section 171.8 of this subchapter), the outage in a bulk packaging must be at least five percent of the total capacity of the tank or compartment at the reference temperature of $46^{\circ} \mathrm{C}\left(115^{\circ} \mathrm{F}\right.$ ) for uninsulated tanks and $41^{\circ} \mathrm{F}$ (105 ${ }^{\circ} \mathrm{F}$ ) for insulated tanks.

This requirement: [ ] Does not apply. . [ ] Applies; indicate the following.

Addressed in:

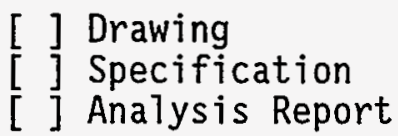

[ ] Operating Instruction
[ ] Manufacturer Supplied Data
[ ] Similarity or Documented Record

Specify: 


\subsection{4b (b) Stainless Steel Substitution.}

Equivalent steel. For the purposes of this section, stainless steel is steel with a guaranteed minimum tensile strength of 51.7 deka newtons per square millimeter $(75,000 \mathrm{ps} i)$ and a guaranteed elongation of 40 percent or greater. Where the regulations permit steel other than stainless steel to be used in place of a specified stainless steel (for example, as in section 172.102 of this subchapter, special provision B30), the minimum thickness for the steel must be obtained from one of the following formulas, as appropriate: Formula for metric units:

$e_{q}=\left(12.74 e_{0}\right) /\left(R m_{1} A_{1}\right)^{1 / 3}$

Formula for non-metric units:

$e_{1}=\left(144.2 e_{0}\right) /\left(R m_{1} A_{1}\right)^{1 / 3}$

Where:

$e_{0}=$ Required thickness of the reference stainless steel in millimeters or inches respectively;

$e_{1}=$ Equivalent thickness of the steel used in millimeters or inches respectively; $\mathrm{Rm}_{1}=$ specified minimum tensile strength of the steel used in deka newtons per square millimeter or pounds per square inch respectively; and

$A_{1}=$ Specified minimum percentage elongation of the steel used multiplied by 100 (for example, 20 percent times 100 equals 20 ). Elongation values used must be determined from a $50 \mathrm{~mm}$ or 2 inch test specimen.

This requirement: [ ] Does not apply. [ ] Applies; indicate the following. Addressed in:
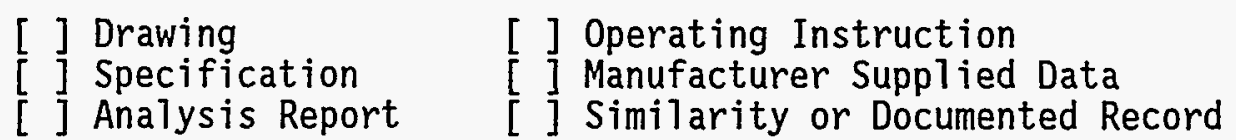

Specify:

\subsection{4b (c) Pressurized Loading:}

Air pressure in excess of ambient atmospheric pressure may not be used to load or unload any lading which may create an air-enriched mixture within the flamability range of the lading in the vapor space of the tank.

This requirement: [ ] Does not apply. [ ] Applies; indicate the following.

Addressed in:

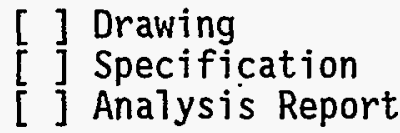
[ ] Operating Instruction
[ ] Manufacturer Supplied Data
[ ] Similarity or Documented Record

Specify: 
DOT-7A TYPE A

PACKAGING QUALIFICATION CHECKLIST

\subsection{CFR 173.411 General design requirements.}

\subsection{1 (a) Handling and Securing.}

Except for a package that contains a limited quantity or excepted instrument or article under sections 173.421 through 173.424 , each package used for shipment of radioactive materials shall be designed so that:

(a) The package can be easily handled and properly secured in or on a conveyance during transport;

This requirement: [ ] Does not apply.

[ ] Applies; indicate the following.

Addressed in:

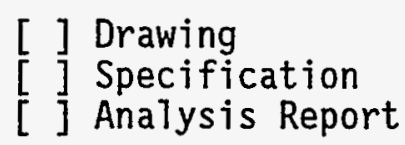
[ ] Operating Instruction
] Manufacturer Supplied Data
[ ] Similarity or Documented Record

Specify:

\subsection{1 (b) Manual Handling.}

A package with a gross weight exceeding 10 kilograms (22 pounds) and up to 50 kilograms ( 110 pounds) has a means for manual handling;

This requirement: [ ] Does not apply. [ ] Applies; indicate the following.
Addressed in:
[ ] Drawing
[ ] Specification
[ ] Analysis Report
[ ] Operating Instruction
[ ] Manufacturer Supplied Data
[ ] Similarity or Documented Record

Specify: 


\subsection{1 (c) Mechanical Handling.}

A package with a gross weight of 50 kilograms (110 pounds) or more can be safely handled by mechanical means;

This requirement: [ ] Does not apply. [ ] Applies; indicate the following.

Addressed in:

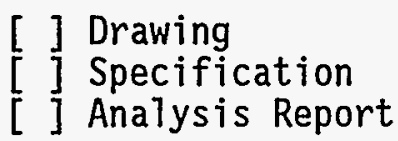
[ ] Operating Instruction
[ ] Manufacturer Supplied Data
[ ] Similarity or Documented Record

Specify:

\subsection{1 (d) Lifting Attachments.}

Each lifting attachment on the package, when used in the intended manner, with a minimum safety factor of three, does not impose an unsafe stress on the structure of the package. In addition, the lifting attachment shall be so designed that failure under excessive load would not impair the ability of the package to meet all other requirements of this subpart. Each attachment or other feature on the outer surface of the packaging that could be used to lift the package must be removable or otherwise capable of being made inoperable for transport, or shall be designed with strength equivalent to that required for lifting attachments;

This requirement: [ ] Does not apply. [ ] Applies; indicate the following.

Addressed in:
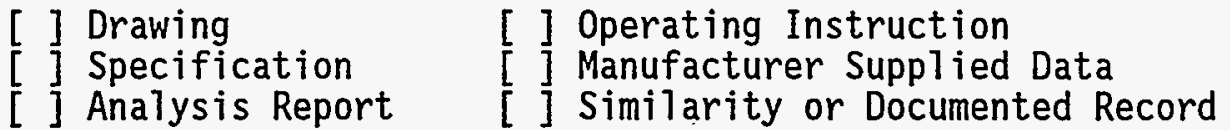

Specify: 


\subsection{1 (e) External Surface Decontamination.}

The external surface, as far as practicable, may be easily decontaminated;

This requirement: [ ] Does not apply. [ ] Applies; indicate the following. Addressed in:

Specify:

\subsection{1 (f) Outer Layer - Pockets, Crevices (Water Collection).}

The outer layer of packaging will avoid, as far as practicable, pockets or crevices where water might collect; and

This requirement: [ ] Does not apply. [ ] Applies; indicate the following. Addressed in:

Specify: 
DOT-7A TYPE A

PACKAGING QUALIFICATION CHECKLIST

\subsection{1 (g) Features Added at Time of Transport.}

Each feature that is added to the package at the time of transport, and that is not a part of the package, will not reduce the safety of the package.

This requirement: [ ] Does not apply. [ ] Applies; indicate the following.

$\begin{array}{lll}\text { Addressed in: } & \text { [ ] Drawing } & \text { [ ] Operating Instruction } \\ & {[\text { ] Specification }} & \text { [ ] Manufacturer Supplied Data }\end{array}$

[ ] Analysis Report [ ] Similarity or Documented Record

Specify: 


\subsection{CFR 173.412 Additional design requirements for Type A packages.}

\subsection{Smallest External Dimension.}

In addition to meeting the general design requirements prescribed in section 173.411 , each Type A packaging shall be designed so that:

(a) The smallest overall external dimension of the package is not less than 10 centimeters (4 inches):

This requirement: [ ] Does not apply. Addressed in:

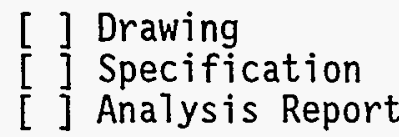

[ ] Applies; indicate the following.

[ ] Operating Instruction

[ ] Manufacturer Supplied Data

[ ] Similarity or Documented Record

Specify:

\subsection{2 (b) Tamper Indication.}

The outside of the packaging incorporates a feature, such as a seal, that is not readily breakable, and that, while intact, is evidence that the package has not been opened. In the case of packages shipped in exclusive use closed transport vehicles, the cargo compartment may be sealed instead of the individual packages;

This requirement: [ ] Does not apply. [ ] Applies; indicate the following. Addressed in:

$$
\begin{aligned}
& \text { [ ] Drawing } \\
& {[\text { Specification }} \\
& \text { [ ] AnaTysis Report }
\end{aligned}
$$$$
\begin{aligned}
& \text { [ ] Operating Instruction } \\
& \text { [ ] Manufacturer Supplied Data } \\
& \text { [ ] Similarity or Documented Record }
\end{aligned}
$$

Specify: 
173.412 (c) External Surface Protrusions, Decontamination.

As far as practicable, the external surfaces are free from protrusions and are designed and finished so that they can be easily decontaminated;

This requirement: [ ] Does nọt apply. [ ] Applies; indicate the following.

Addressed in: [ ] Drawing

[ ] Specification

[ ] Analysis Report

[ ] Operating Instruction

[ ] Manufacturer Supplied Data

[ ] Similarity or Documented Record

Specify:

\subsection{2 (d) Containment and Shielding.}

Containment and shielding would be maintained during transportation and storage in a temperature range of $-40^{\circ} \mathrm{C}\left(-40^{\circ} \mathrm{F}\right)$ to $70^{\circ} \mathrm{C}\left(158^{\circ} \mathrm{F}\right)$ with account being taken of the possibility of brittle fracture;

This requirement: [ ] Does not appiy. [ ] Applies; indicate the following.

Addressed in:

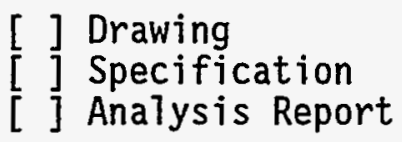

[ ] Operating Instruction

[ ] Manufacturer Supplied Data

[ ] Similarity or Documented Record

Specify: 
PACKAGING QUALIFICATION CHECKLIST

\subsection{2 (e) Acceleration, Vibration.}

It is able to withstand the effects of any acceleration, vibration, or vibration resonance that may arise during normal transportation, without any deterioration of the effectiveness of closing devices or of the integrity of the package as a whole and without loosening or unintentional release of nuts, bolts, or other securing devices even after repeated use;

This requirement: [ ] Does not appiy. [ ] Applies; indicate the following. Addressed in:

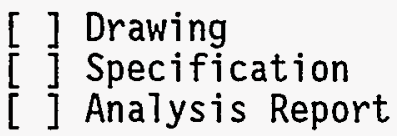

[ ] Operating Instruction [ ] Manufacturer Supplied Data [ ] AnaTysis Report [ ] Similarity or Documented Record

Specify:

\subsection{2 (f) Secure Containment System.}

It includes a containment system securely closed by a positive fastening device that cannot be opened unintentionally or by pressure that may arise within the package during normal transport. special form, as demonstrated in accordance with section 173.469 may be considered as a component of the containment system;

This requirement: [ ] Does not apply. [ ] Applies; indicate the following. Addressed in:

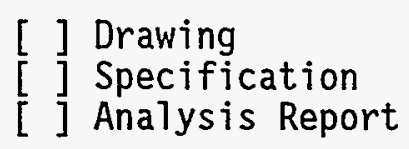
[ ] Operating Instruction Manufacturer Supplied Data ] Similarity or Documented Record

Specify: 


\subsection{2 (g) Physical/Chemical Compatibility, Irradiation.}

The materials of the packaging and any components or structures are physically and chemically compatible with each other and with the contents, taking into account the behavior of each under irradiation:

This requirement: [ ] Does not apply.

[ ] App]ies; indicate the following.

Addressed in:

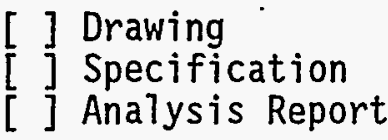
[ ] Operating Instruction
[ ] Manufacturer Supplied Data
[ ] Similarity or Documented Record

Specify:

173.412 (h) Radiolytic Decomposition, Chemical Reaction, Radiolysis.

For each component of the containment system account is taken, where applicable, of radiolytic decomposition of materials and the generation of gas by chemical reaction and radiolysis:

This requirement: [ ] Does not apply. [ ] Applies; indicate the following.

Addressed in:

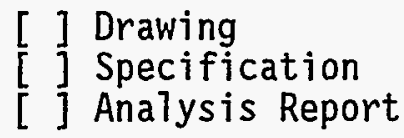

[ ] Operating Instruction

[ ] Manufacturer Supplied Data Analysis Report [ ] Similarity or Documented Record

Specify: 


\subsection{2 (i) Reduction of Ambient Pressure.}

The containment system will retain its radioactive contents under the reduction of ambient pressure to $.25 \mathrm{ki}$ lograms per square centimeter ( 3.5 pounds per square inch);

This requirement: [ ] Does not apply. [ ] Applies; indicate the following. Addressed in:

Specify:

\subsection{2 (j) Valve - Protection, Enclosure.}

Each valve through which the radioactive contents could otherwise escape is protected against damage and unauthorized operation and, except for a pressure relief device, has an enclosure to retain any leakage;

This requirement: [ ] Does not apply. [ ] Applies; indicate the following. Addressed in:

Specify: 


\subsection{2 (k) Shielding (Enclosure).}

Any radiation shield that encloses a component of the packaging specified as part of the containment system will prevent the unintentional escape of that component from the shield;

This requirement: [ ] Does not apply. [ ] Applies; indicate the following. Addressed in:

Specify:

\subsection{2 (1) Tiedown (Failure).}

Failure of any tiedown attachment on the packaging under excessive load will not impair the ability of the package to meet other requirements of this subpart;

This requirement: [ ] Does not apply. [ ] Applies; indicate the following. Addressed in:

Specify: 


\title{
$173.412(\mathrm{~m})$ Evaluation and Testing.
}

\begin{abstract}
When subjected to the tests specified in section 173.465 or evaluated against these tests by any of the methods authorized by section $173.461(a)$, the packaging will prevent:

(1) Loss or dispersal of the radioactive contents; and

(2) Any significant increase in the radiation levels recorded or calculated at the external surfaces for the condition before the test;
\end{abstract}

\section{This requirement will be addressed by the test facility.}

\subsection{2 (n) Evaluation and Testing of Liquid Packagings.}

Each packaging designed for liquids will:

(1) Meet the conditions prescribed in paragraph (m) of this section when subjected to the tests specified in section 173.466 or evaluated against these tests by any of the methods authorized by section $173.461(a)$;

\section{This requirement will be addressed by the test facility.}

(2) For any package with a liquid volume not exceeding 50 cubic centimeters $(1.7$ fluid ounces), have sufficient suitable absorbent material to absorb twice the volume of the liquid contents. The absorbent material shall be compatible with the package contents and suitably positioned to contact the liquid in the event of leakage; and (3) For any package with a liquid volume exceeding 50 cubic centimeters ( 1.7 fluid ounces), either:

(i) Have sufficient absorbent material as prescribed in paragraph $(n)(2)$ of this section; or

(ii) Have a containment system composed of primary inner and secondary outer containment components designed to assure retention of the liquid contents with in the secondary outer components in the event that the primary inner components leak; and

This requirement: [ ] Does not apply. [ ] Applies; indicate the following. Addressed in:

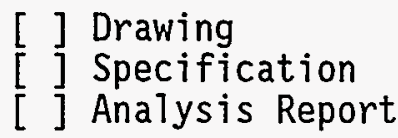

\author{
[ ] Operating Instruction \\ [ ] Manufacturer Supplied Data \\ [ ] Similarity or Documented Record
}

Specify:

\subsection{2 (o) Evaluation and Testing of Gas Packagings.}

Each package designed for compressed or uncompressed gases other than tritium or argon-37 not exceeding 200 curies will be able to prevent loss of contents when the package is subjected to the tests prescribed in section 173.466 or evaluated against these tests by any of the methods authorized by section $173.461(a)$.

This requirement will be addressed by the test facility. 


\subsection{CFR 178.3 Marking of Packagings}

\section{3 (a) What and How to Mark.}

Each packaging manufactured to a DOT specification or a UN Standard shall be marked as follows:

(1) In an unobstructed area, with letters, and numerals identifying the standards or

specification (e.g., UN 1A1, DOT 4B240ET, etc.).

(2) Untess otherwise specified in this part, with the name and address or symbol of the manufacturer, or, for a UN standard packaging, the approval agency certifying compliance with the UN standard. Symbols, if used, must be registered with the Associate Administrator for Hazardous Materials Safety. Duplicative symbols are not authorized.

(3) .The markings must be stamped, embossed, burned, printed or otherwise marked on the packaging to provide adequate accessibility, permanency, contrast, and legibility so as to be readily apparent and understood.

(4) Unless otherwise specified, letters and numerals must be at least $12.0 \mathrm{~mm}(0.47$ inches) in height except that for packagings of less than or equal to $30 \mathrm{~L}$ (7.9 gallons) capacity for liquids or $30 \mathrm{~kg}$ ( 66 pounds) capacity for solids the height must be at least $6.0 \mathrm{~mm}(0.2$ inches).

This requirement: [ ] Does not apply.

[ ] Applies; indicate the following.

Addressed in:

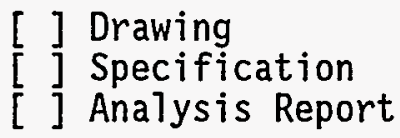

[ ] Operating Instruction

[ ] Manufacturer Supplied Data

[ ] Similarity or Documented Record

Specify: 


\section{3 (b) Marking.}

Packagings may be marked with the United Nations symbol and packaging identification code as provided in this subchapter, in the ICAO Technical Instructions or in Annex 1 to the IMDG Code, provided the person applying these marks has established that the packaging conforms to the applicable provisions of this subchapter, the ICAO Technical Instructions or Annex 1 to the IMDG Code, respectively.

(1) If an indication of the State in whose territory the specified tests are carried out, or of the Stat authorizing the allocation of the mark, is required by this part (see section 178.503 of this part), the letters "USA" shall be used if the manufacturing and testing occurs in the United States.

(2) If an indication of the name of the manufacturer or other identification of the packaging as specified by the competent authority is required, the name and address or symbol of the person making the mark shall be entered. Symbols, if used, must be registered with the Associate Administrator for hazardous Materials Safety. Duplicate symbols are not authorized. (3) Packagings manufactured to UN standards in accordance with this subchapter shall be marked as prescribed in section 178.503 of this part.

This requirement: [ ] Does not apply. . [ ] Applies; indicate the following.

Addressed in: [ ] Drawing [ ] Specification [ ] Operating Instruction
[ ] Manufacturer Supplied Data
[ ] Similarity or Documented Record

Specify:

\section{3 (c) Multiple Markings.}

Where a packaging conforms to more than one UN standard or DOT specification, the packaging may bear more than one marking, provided the packaging meets all the requirements of each standard or specification. Where more than one marking appears on a packaging, each marking must appear in its entirety.

This requirement: [ ] Does not apply.

[ ] Applies; indicate the following.

Addressed in:

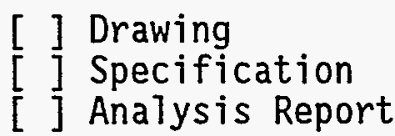

[ ] Operating Instruction
[ ] Manufacturer Supplied Data
[ ] Similarity or Documented Record

Specify: 
DOT-7A TYPE A

PACKAGING QUALIFICATION CHECKLIST

\subsection{0ther Items}

Enclose a copy of the following documents with this completed checklist and forward to the DOE/HQ-approved test facility. The name and address of the test facility are provided when a docket is opened as discussed in Section 5.0:

- Packaging drawing

- Packaging specification (if developed)

- Analysis report

- Operating instruction.

\section{Completion}

Applicant:

Signature Date

Name (print)/

Company/

Address

Phone:

\section{Test Facility Use Only}

Document review:

Test engineer (sign/date)

Reviewed by: (sign/date)

Packaging drawing

Packaging specification

Analysis report

Operating instruction

Packaging Qualification Checklist 